\title{
The Role of Gravity Waves in the Formation and Organization of Clouds During TWPICE
}

\section{DE-SC0002521}

\section{Michael Reeder, Todd Lane, Mai Chi Nguyen Hankinson}

One of the important features of the research is that it makes use of the observations of tropical convection taken during TWP-ICE, which are of unprecedented quality and scope. While the field experiment was not explicitly designed to examine research areas associated with convectively generated gravity waves, the observations taken are well suited nonetheless for such an investigation, especially in support of a program of numerical modelling. From this perspective the proposed research adds greater value to TWP-ICE. Another important feature of the research plan is that it strongly emphasises the synthesis and comparison of models with observation, making model evaluation one of the key components of the project. The results of this research are summarized below.

\section{Analysis of Inertia-Gravity Waves}

The results of this part of the project have been submitted for publication in the Journal of Geophysical Research [Hankinson, C. M. N., M. J. Reeder and T. P. Lane. 2013. Gravity waves generated by convection during TWP-ICE Part I: Inertia-gravity waves. J. Geophys. Res. (submitted)]. The main aim of this part of the project is to deduce the properties of low-frequency convectively generated gravity waves from the radiosonde observations made during TWP-ICE. The radiosonde soundings from five stations (Cape Don, Darwin, Garden Point, Mount Bundy and Point Stuart) are the main data used here. The vertical soundings of wind speed and direction, air temperature, mixing ratio, pressure and the altitude of the balloon are available every 3 hours with the time resolution of 2 seconds (except for Darwin where the soundings are only available every 6 hour). The zonal and meridional wind components ( $\mathrm{u}$ and $\mathrm{v}$, respectively) are derived from wind speed and direction. Subsequently, the profiles of horizontal wind components ( $u$ and $v$ ), temperature $\mathrm{T}$, mixing ratio $\mathrm{q}$ and pressure $\mathrm{p}$ are interpolated to a regular grid of $15 \mathrm{~m}$ resolution, up to a height of $30 \mathrm{~km}$. As the tropopause is located near $17 \mathrm{~km}$ altitude during the campaign, most of the analysis of the data is confined to the altitude range $17.5-28 \mathrm{~km}$. In addition, some analysis of high frequency waves use data from the troposphere, in the range $3-10 \mathrm{~km}$ altitude, which is the portion of the troposphere in which vertical temperature gradient is relatively constant.

The perturbations of $\mathrm{u}, \mathrm{v}$ and $\mathrm{T}$ (denoted as $\mathrm{u}^{\prime}, \mathrm{v}^{\prime}$ and $\mathrm{T}^{\prime}$ respectively) are calculated by subtracting mean profiles. These mean profiles are constructed using the variational analysis from the observed profiles during the TWP-ICE campaign [Xie et al., 2010]. These profiles represent the time evolving spatial average conditions in a $2 \times 2$ degree box centered on the campaign area. The basic assumption under-pinning the analysis is that these perturbations physically represent gravity waves. Two additional methods of defining the mean state were tested to access the sensitivity of the results to the choice of mean state. First, the mean state was defined as the time tendencies of the observations at each height. Second, the mean state was defined by a polynomial fitted to each vertical profile using least squares. Overall, the different mean states gave similar pattern of perturbations, although their magnitudes could be different by a few $\mathrm{m} \mathrm{s}^{-1}$.

Figure 1 shows the time-height evolution of the zonal wind perturbations at Point Stuart. The 
evolution of the meridional wind (not shown) is similar to that of zonal wind. Likewise the temperature perturbations are similar with amplitude of about $10 \mathrm{~K}$. The time-height evolution of the zonal wind perturbations show downward phase propagation, which is one of the characteristics of upward propagating gravity waves. Two distinct regimes are found, during which the propagating characteristics of the perturbations are quite different. The gravity waves in each regime have been analyzed separately.

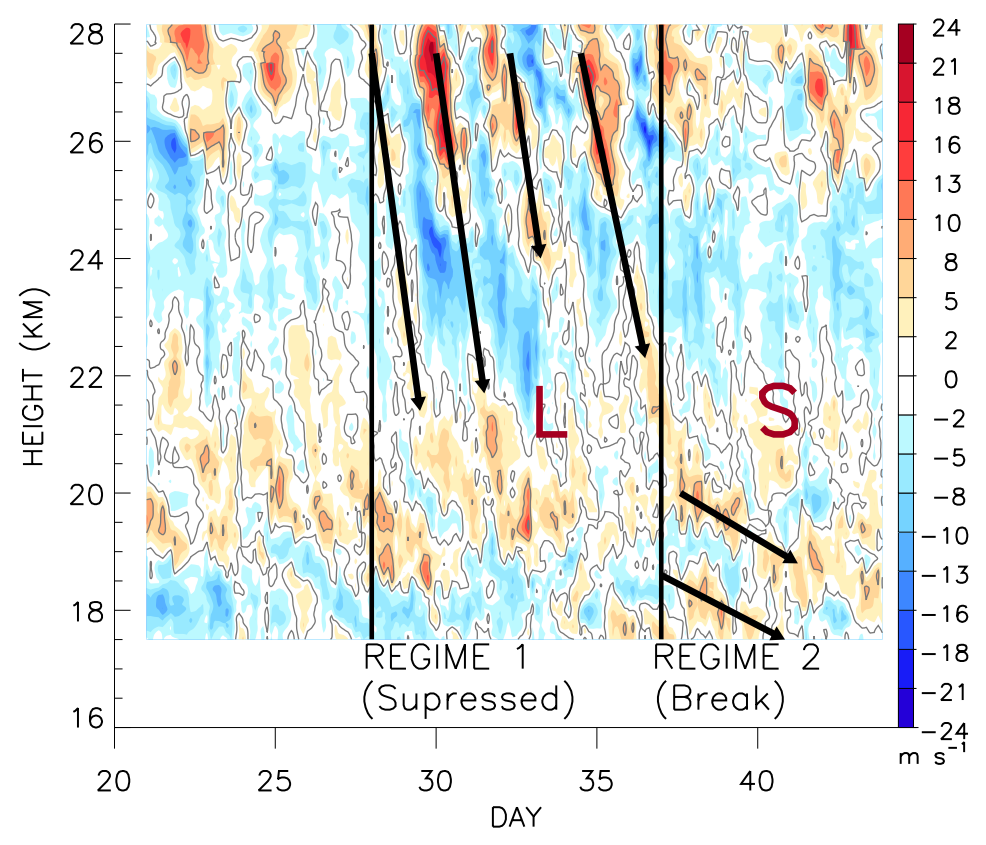

Figure 1. Time-height evolution of the zonal wind perturbations at the station Point Stuart. Positive values are contoured. The mean state is taken from the variational analysis. Arrows mark the descending phase propagation.

In the first regime (28 January - 6 February), large amplitude perturbations (of the order of $18-20$ $\mathrm{m} \mathrm{s}^{-1}$ ) with clearly descending phase propagation are evident in the $22-28 \mathrm{~km}$ altitude range. This regime sits in the later part of the suppressed monsoon and the clear day periods identified by May et al. [2008]. The second regime ( 7 - 13 February) coincides with the monsoon break period. In this regime the downward phase propagation is most clearly evident below the heights of $22 \mathrm{~km}$. Compared with the wave characteristics in Regime 1, these perturbations have smaller downward phase speeds and smaller vertical wavelengths. Although there are similar descending-phase perturbations in the lower stratosphere during Regime 1, they are dominated by the signals at the higher altitudes.

The ground-based frequency-vertical wavenumber quadrature power spectra are calculated (and averaged over all stations) for the horizontal wind perturbations during Regimes 1 and 2. The quadrature spectra are defined using Fourier analysis as the imaginary part of cross spectrum of the two horizontal components of the velocity. During Regime 1, the quadrature spectrum for waves of group L peaks at a ground-based period of 2.3 days and vertical wavelength of $5.2 \mathrm{~km}$. During Regime 2, waves of group S have a ground-based period near 3.5 days and the vertical wavelengths in the range of 1.5 to $2.1 \mathrm{~km}$. The properties of waves of groups $\mathrm{L}$ and $\mathrm{S}$ noted above are consistent with the phase lines marked by the arrows in Fig. 1. 
Wave groups $\mathrm{L}$ and $\mathrm{S}$ are further investigated by backward ray tracing to understand their origins and association with convective sources. For this purpose, the program suite GROGRAT, which is developed and described by Marks and Eckermann [1995], is employed using wind and temperature fields from the 6-hourly ERA Interim reanalysis. The type of convection along each ray is identified following the method of Inoue [1987] using hourly infrared satellite data from MTSAT. The presence of convection in each section between two consecutive points along the ray is defined if the area covered by convection is at least $10 \%$ in a $2 \times 2$ degree box centered at the middle of the section. In the case of long sections, the box is expanded to fit the whole section. Figure 2 shows rays from group L traced backward from 00 UTC 04 February. The rays originate mainly from the area $123 \mathrm{E}-127 \mathrm{E}$ and $7 \mathrm{~S}-0.5 \mathrm{~S}$ near Indonesia where deep convection is analyzed. While passing this deep convection region, the rays are in the middle troposphere from $3-17 \mathrm{~km}$ (not shown). Thus, it appears that these waves were generated by deep convection in this region.

\section{Analysis of High-Frequency Gravity Waves}

This results from this part of the project have been reported in a paper submitted to the Journal of Geophysical Research [Hankinson, C. M. N., M. J. Reeder and T. P. Lane. 2013. Gravity waves generated by convection during TWP-ICE. Part II: High-frequency waves. J. Geophys. Res. (submitted)]. In general, high-frequency gravity waves are difficult to observe, as they tend to propagate rapidly upwards. Consequently, these waves are most commonly observed near the place and time of their generation. High-frequency gravity waves have been observed with radars and satellites. From radar data, the horizontal wavelength and frequency of the waves can be observed directly. The area covered by the radar, however, limits these data. From satellite data (e.g. airglow images), the horizontal wavelength and ground-based phase velocity are observed directly. Although satellites cover large areas, the observations of the high-frequency gravity waves are contingent on the waves reaching the upper atmosphere (e.g. at $80-100 \mathrm{~km}$ altitudes).

Using radiosonde data, Lane et al [2003], Geller and Gong [2010] and Gong and Geller [2010] deduced the wave activity and frequencies of the high-frequency gravity waves. Radiosonde data are available globally and for long times, but they are limited by relatively coarse time resolution (typically 3 to 12 hours between two consecutive observations). Moreover, the vertical wavelengths cannot be calculated from the sounding directly (Lane et al. [2003]). For all these reasons, there is a need for detailed observation of high-frequency gravity waves. The main aspects of the highfrequency gravity waves addressed here include their vertical and temporal variations, and their relationship with the rain rate, which is a proxy for the diabatic heating rate.

In the high-frequency range, properties of gravity waves are determined using perturbations of the vertical velocity derived from balloon's ascent rates [Lane et al., 2003]. The intrinsic period of these waves are found to be in the range of $20-40$ minutes using the perturbation energy method of Geller and Gong [2010]. 


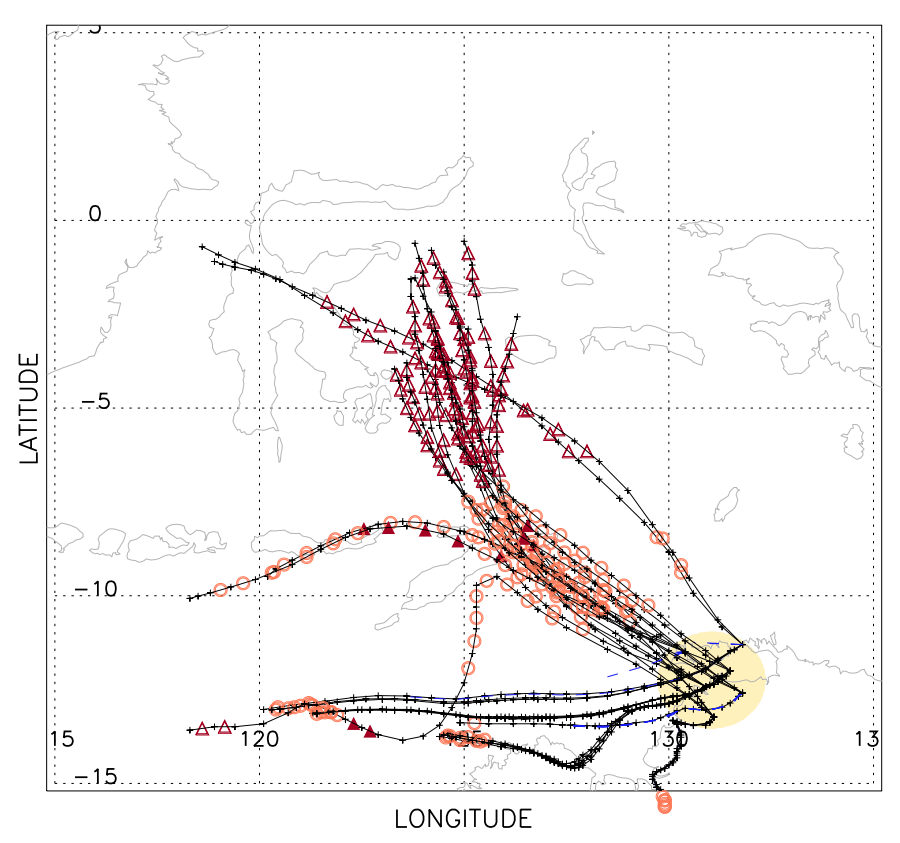

Figure 2. Backward ray tracing for groups L (arriving at 00Z 04/02/2006). Horizontal plane view. Black solid (dashed blue) lines show rays that do (do not) pass over regions with convective activity of deep (red triangles) and/or shallow (brown circles) convection. Shaded areas show the radar coverage during TWPICE. Distance is calculated from the location of C-Pol radar at $\left(131.044^{\circ} \mathrm{E}, 12.249^{\circ} \mathrm{S}\right)$.

Figure 3 shows the time-height evolution of the wave activity $\rho w^{2}$ (derived from the ascent rate) averaged over all stations during Regimes 1 and 2 . The strongest wave activity is concentrated in the layer below $22 \mathrm{~km}$, indicating that the layer above filters the waves. Furthermore, the time series of the wave activity averaged over heights of $17.5-28 \mathrm{~km}$ exhibits a pulse-like pattern. This temporal variation of the $17.5-28 \mathrm{~km}$ mean wave activity is analyzed using a Morlet wavelet transform. During Regime 1, the wave activity varies predominantly with a $3-4$ day period, but varies mostly with a 1-day period during Regime 2 . While the 1-day period variation of the highfrequency gravity wave activity can be explained by the diurnal variation of the convection during the monsoon break (Regime 2), the origin of the $3-4$ day variation during Regime 1 is related to the passage of tropical synoptic systems.

Precipitation estimates from C-pol radar are available every 10 minutes on a $2.5 \times 2.5 \mathrm{~km}$ grid. In addition to the rainfall rates, rainfall type (either convective, stratiform or mixed), determined by the method developed by Steiner et al. [2004], is available at each gridpoint. The rainfall and area for each type are accumulated over the 3-hour periods centered at the observation times. These data have been used to relate the activity of high frequency waves to the diabatic heating implied by rainfall. 


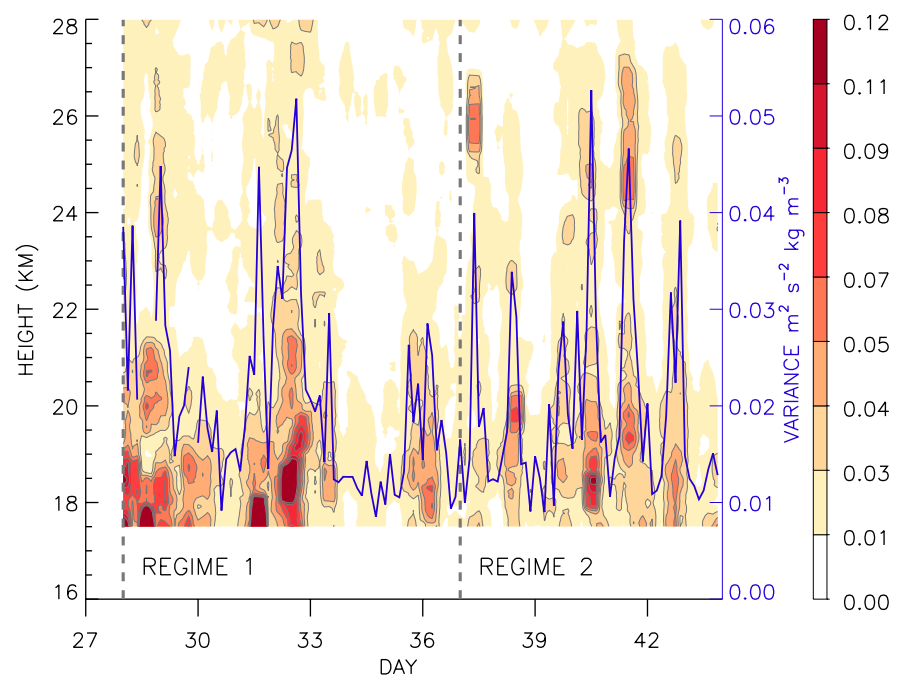

Figure 3. Evolution of high-frequency wave activity $\rho \mathrm{w}^{\prime 2}$ in the stratosphere.

The relationship between the wave activity and rain rate, which is a proxy for the diabatic heating by convection, is not a simple positive relation. At low rain rates, the wave activity increases as the rain rates increase, whereas there is no clear relationship between them at high values of rain rates associated with deep convective clouds. This result implies that diabatic heating, which is largely assumed as the main mechanism for gravity waves generation by convection, is not the only mechanism generating, especially for deep, precipitating convection.

The 3 - 4 day modulation of the wave activity during the suppressed monsoon regime and its concentration in the lower part of the stratosphere is investigated further by examining the propagation properties of the medium and the variation of the wave source. It is found that the propagation properties (namely the Scorer parameter) of the layer between $22-26 \mathrm{~km}$ are do not permit the transmission of short waves propagating to the east (upstream). Thus, the presence of this layer is consistent with the decrease of the wave activity with height. However, the variation in the propagation properties of the medium cannot explain for the $3-4$ day period variation of the wave activity. Instead, the $3-4$ day variation is consistent with the variation of the convection in the region within $300 \mathrm{~km}$ of the TWP-ICE domain.

\section{WRF Simulations of the Convection and the Associated Waves Field}

The convection and gravity waves observed during TWP-ICE are simulated with the Weather Research and Forecasting (WRF) Model (Skamarock et al. 2005). These simulations are compared with radiosonde observations described above and are used to determine some of the properties of convectively generated gravity waves. The results from this part of the project are currently being written up for publication in the Journal of Geophysical Research.

The model is configured as follows. There are 140 vertical levels to a height of $1 \mathrm{hPa}$, high resolution in the stratosphere, a $15 \mathrm{~km}$ damping layer at the top, 4 nested, two-way interacting grids with the horizontal spacings of $33 \mathrm{~km}, 11 \mathrm{~km}, 3.7 \mathrm{~km}$ and $1.2 \mathrm{~km}$ respectively. Figure $4 \mathrm{a}$ shows the arrangement of model grids. The physics options are: Thompson microphysics, Kain-Fritsch convective scheme for the outer two domains only, the RRTM scheme for long wave radiation, the 
Dudhia scheme for short wave radiation, a Monin-Obukhov surface layer, and the unified Noah land-surface model. The initial and boundary conditions come from the ERA-Interim re-analyses.
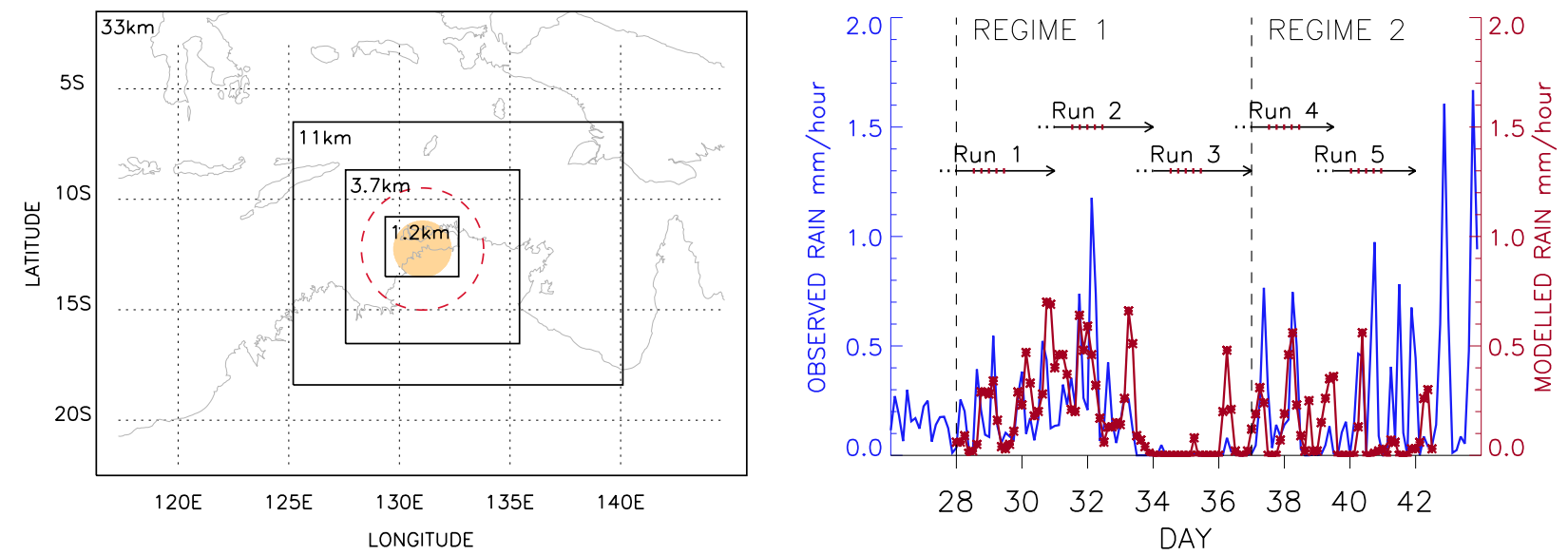

Figure 4. a) Simulation domains. Shaded area indicates the area covered by the radar during TWPICE. b) Simulated (red line with asterisks) and observed (blue solid line) rainfall averaged over the radar area.

Five overlapping simulations are conducted covering the period from 1200 UTC 27 January to 0000 UTC 12 February 2006 (see arrows in Fig. 4b). Each simulation is integrated for 3 days and 12 hours, the first 12 hours of which overlap with the previous simulation. These periods of overlap cover the model spin up and are not analysed. Figure $4 \mathrm{~b}$ shows that the simulated precipitation averaged over radar area compares well with the observations albeit with smaller peaks.

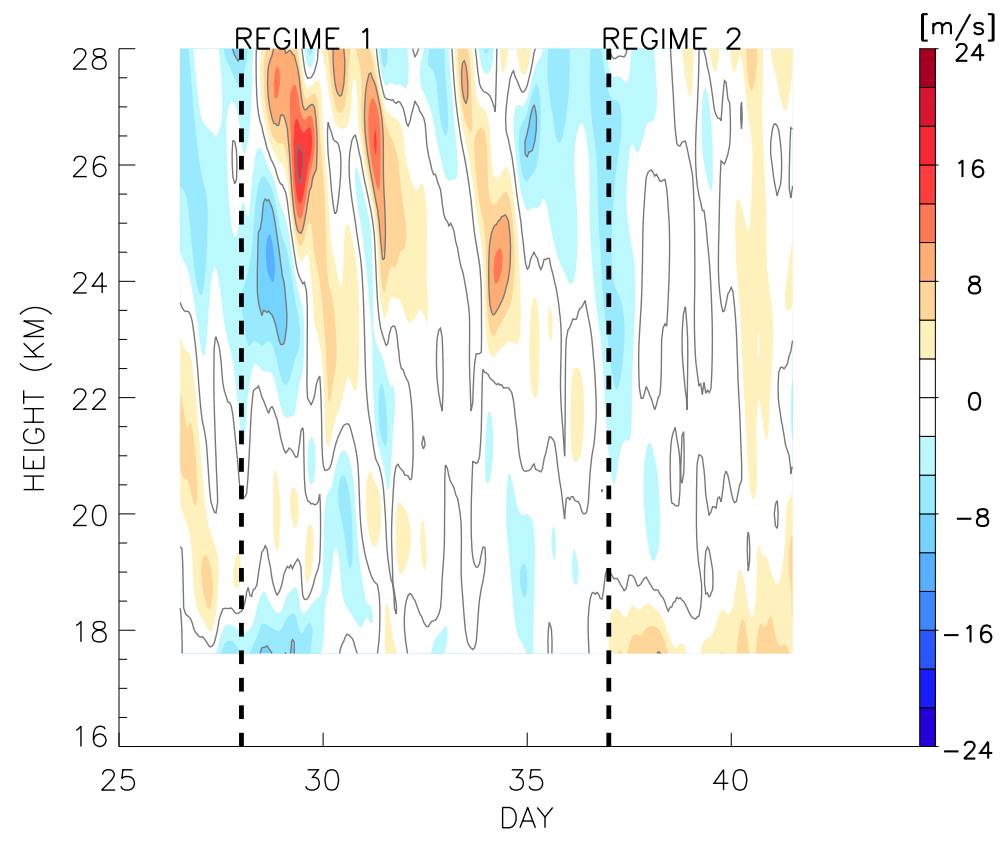

Figure 5. Time-height evolution of the simulated zonal wind perturbations at the station Point Stuart by the innermost grid. 
The low-frequency inertia-gravity waves appear to be well simulated by the model. Figure 5 shows, similar to Fig. 1, the evolution of the zonal wind perturbations simulated by the model. Wave group $\mathrm{L}$ can be seen clearly with descending phase lines during the suppressed monsoon period. The phase lines, however, corresponding to wave group $\mathrm{S}$ are not shown clearly by the model simulation.

The high-frequency gravity waves simulated by the model are analysed by examining the vertical velocity field. During the suppressed monsoon regime, relatively linear wave fronts suggest that the gravity waves were generated elsewhere and propagate into the domain. In contrast, during the monsoon break regime, short horizontal wavelengths with circular wave fronts indicate that these gravity waves were generated by local convection within the domain.

The high-resolution model simulations provide a more complete picture of the wave field than that provided by the radiosonde profiles. For example, the horizontal wavelength and phase speeds of the high-frequency gravity waves can be determined. Figure 6 shows the zonal wavenumberfrequency spectra of vertical velocity at $22 \mathrm{~km}$ on day 32 (during the suppressed monsoon) and on day 38 (during the monsoon break). On day 32 (panel a), the dominant wave has a horizontal zonal wavelength of about $40 \mathrm{~km}$, a period between 30 minutes and 1 hour, a vertical wavelength of about $8 \mathrm{~km}$ and propagates eastwards with the intrinsic speed of $55 \mathrm{~ms}^{-1}$. In contrast, on day 38, the dominant waves have smaller horizontal wavelengths, between 7 and $20 \mathrm{~km}$, periods between 30 minutes and 1 hours, vertical wavelengths less than $2 \mathrm{~km}$, and propagate to both the east and west. These properties are consistent with the waves generated within the model domain and propagating outwards from their source.
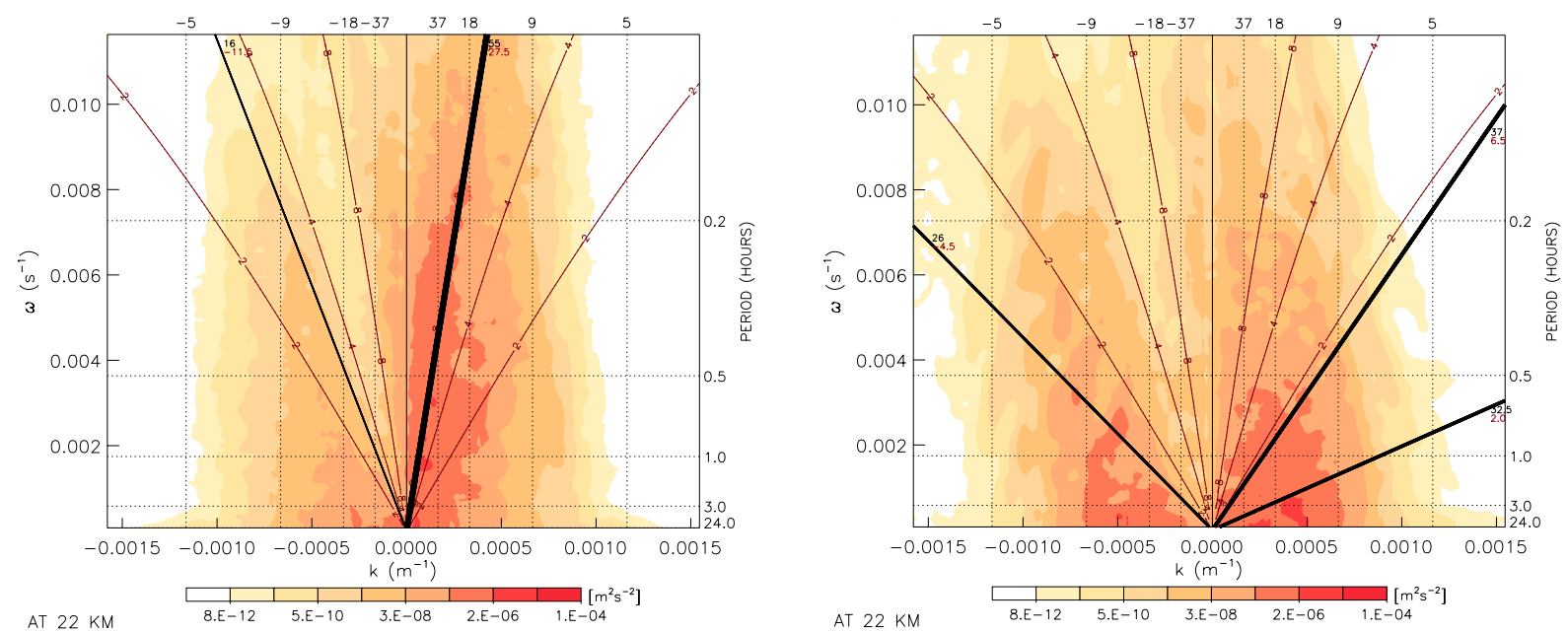

Figure 6. a) Zonal wavenumber-frequency spectra of the vertical velocity at $22 \mathrm{~km}$ during a) the suppressed monsoon (day 32) and b) the monsoon break (day 38). Black lines show zonal phase speeds, red thin lines indicate vertical wavelengths in $\mathrm{km}$. 
Figure 7 shows the relationship between the wave activity and the rainfall simulated by the model. The variation of the wave activity is closely related to the variation of rainfall (Fig. 7a). Furthermore, the scatter plot (Fig. 7b) shows a linear relationship between the wave activity and the rain rate during the suppressed monsoon period (blue bars). However, the wave activity appears to be independent of the rain rate at high rain rates during the monsoon break (red triangles). This result is consistent with the radiosonde observations. Moreover, the wave activity is independent of the rain rate over land during the monsoon break, which is consistent with the independence found in the observations for deep convective clouds.

Despite the agreement between the observed and simulated precipitation and its relationship with the wave activity, there are some notable differences between the model and observations. First, the simulated wave activity is roughly an order of magnitude less than the estimates derived from the radiosonde ascent rates. Second, the reduced wave activity in the $24-26 \mathrm{~km}$ layer is not captured in the model simulation. Third, the $3-4$ day variation signal of the wave activity during the suppressed monsoon, although present, does not appear as strong as in the observations.
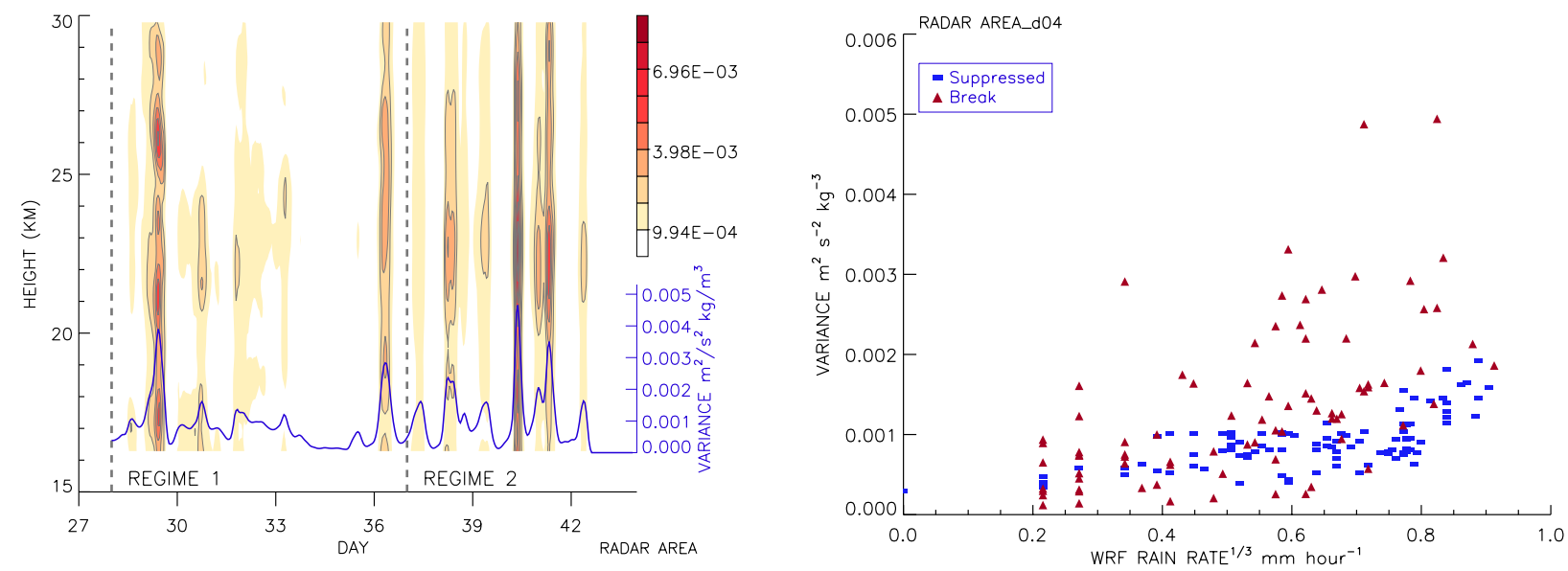

Figure 7. a) Time-height evolution of the wave activity simulated by the model. Blue line shows the averaged wave activity in the layer $17.5-28 \mathrm{~km}$. b) Scatter plot of the wave activity against rain rate during suppressed monsoon (blue bars) and monsoon break (red triangles).

\section{Formation of Cirrus}

This part of the project is progressing and will be completed in the next few months. During TWPICE, cirrus covered the Darwin area in the first half of the suppressed monsoon period and varied diurnally during the monsoon break. This pattern of variation is represented well in the model simulations. Figure 8 shows the variation of the observed (panel a) and simulated (panel b) temperature perturbations and cirrus cover. 

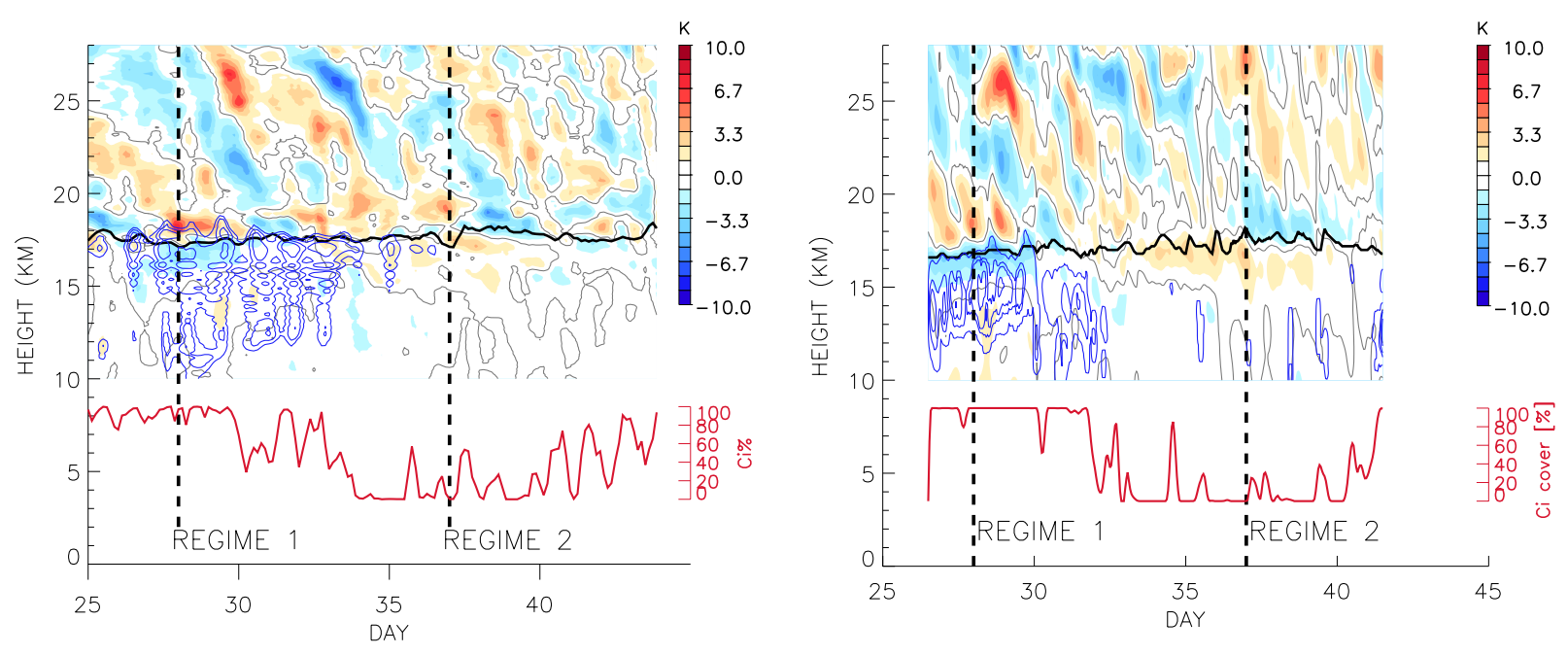

Figure 8. Time-height evolution of temperature perturbations (shaded) in observations (a) and simulations (b). Blue contours show the observed supersaturation over ice (a) and simulated ice content (in b). Red lines show the percentage of the area covered by cirrus within $150 \mathrm{~km}$ from Darwin. In panel a, cirrus cover is taken from the variational analysis dataset. In panel $b$, cirrus is defined as the presence of ice content. Black solid lines show the height of minimum temperature.

The operational radiosonde sounding showed ice supersaturation and oscillations in the wind and temperature field consistent with vertically propagating gravity waves. The simulations using the WRF produce supersaturation with respect to ice and wave features comparable to those observed.

\section{References}

Geller, M. A., and J. Gong, 2010. Gravity wave kinetic, potential, and vertical fluctuation energies as indicators of different frequency gravity waves, J. Geophys. Res., 115, D11,111,doi:10.1029/2009JD012,266

Gong, J., and M. Geller, 2010. Vertical fluctuation energy in United States high vertical resolution radiosonde data as an indicator of convective gravity\}, J. Geophys. Res., 115, D11,110,doi:10.1029/2009JD012,265.

Lane, T. P., M. J. Reeder and F. M. Guest. 2003. Convectively-generated gravity waves observed from radiosonde data taken during MCTEX. Quart. J. Roy. Meteor. Soc. 129, 1731 - 1740.

Marks, C. J., and S. D. Eckermann, 1995. A three-dimensional nonhydrostatic ray-tracing model for gravity waves: Formulation and preliminary results for the middle atmosphere, J. Atmos. Sci., 52, 1959 - 1984.

May, P. T., J. H. Mather, G. Vaughan, C. Jakob, G. M. McFarquhar, K. N. Bower, and G. G. Mace, 2008. The tropical warm pool international cloud experiment, Bull. Amer. Meteorol. Soc., 89, 629 - 645, doi:10.1175/BAMS-89-5-629

Skamarock, W. C., J. B. Klemp, J. Dudhia, D. O. Gill, D. M. Barker, W. Wang, J. G. Powers, 2005. A Description of the Advanced Research WRF Version 2. NCAR Tech Note, NCAR/TN-468+STR, 88 pp. [Available from UCAR Communications, P.O. Box 3000, Boulder, CO 80307].

Steiner, M., M. J. Smith, and R. Uijlenjoet, 2004. A microphysical interpretation of radar reflectivity-rain rate relationships, J. Atmos. Sci., 61, $1114-1131$.

Xie, S., T. Hume, C. Jakob, S. A. Klein, R. B. McCoy, and M. Zhang, 2010. Observed large-scale structures and diabatic heating and drying profiles during TWP-ICE, J. Climate, 23, 57 -9, doi:10.1175/2009JCLI3071.1. 


\section{Gravity Waves Generated by Convection during TWP-ICE. Part I: Inertia-Gravity Waves}

Mai C. N. Hankinson, ${ }^{1}$ M. J. Reeder, ${ }^{1}$ and T. P. Lane ${ }^{2}$

Mai C.N. Hankinson, School of Mathematical Sciences, Monash University, Wellington Road, Melbourne, Victoria 3800, AUSTRALIA. (Mai.C.Nguyen@monash.edu)

M. J. Reeder, School of Mathematical Sciences and ARC Centre for Excellence for Climate System Science, Monash University, Wellington Road, Melbourne, Victoria 3800, AUSTRALIA. (Michael.Reeder@monash.edu)

T. P. Lane, School of Earth Sciences and ARC Centre of Excellence for Climate System Science, The University of Melbourne, Victoria 3010, AUSTRALIA. (tplane@unimelb.edu.au)

${ }^{1}$ School of Mathematical Sciences,

Monash University, Melbourne, Victoria, AUSTRALIA.

${ }^{2}$ School of Earth Sciences, The University of Melbourne, Victoria, AUSTRALIA. 
3 Abstract.

$4 \quad$ Gravity waves are analyzed in radiosonde soundings taken during the TWP-

${ }_{5}$ ICE campaign. The properties of the inertia-gravity waves are analyzed in

- Part I, whereas Part II focuses on high-frequency gravity waves. Two groups

7 of inertia-gravity waves are detected: group L (L stands for Long vertical wave-

s length) in the middle stratosphere during the suppressed monsoon period,

9 and group S (S stands for Short vertical wavelength) in the lower stratosphere

${ }_{10}$ during the monsoon break period. Waves belonging to group L propagate

${ }_{11}$ to the south-east with a mean intrinsic period of $35 \mathrm{~h}$, and have vertical and

${ }_{12}$ horizontal wavelengths of about 5-6 km and 3000-6000 km, respectively. Ray

${ }_{13}$ tracing calculations indicate that these waves originate from a deep convec-

${ }_{14}$ tive region near Indonesia. Waves belonging to group S propagate to the south-

15 south-east with an intrinsic period, vertical wavelength and horizontal wave-

${ }_{16}$ length of about $45 \mathrm{~h}, 2 \mathrm{~km}$ and 2000-4000 km, respectively. These waves are

${ }_{17}$ shown to be associated with shallow convection in the oceanic area within

18 about $1000 \mathrm{~km}$ of Darwin. 


\section{Introduction}

20 Gravity waves can transport momentum and energy large distances from the site of ${ }_{21}$ their generation, exerting a stress on the atmosphere as they dissipate. Although the ${ }_{22}$ effect of individual wave packets on the momentum budget of the atmosphere is small, ${ }_{23}$ the long term accumulated effects are important in climate [see, for example, the recent ${ }_{24}$ review by Alexander et al., 2010].

The present two-part study focuses on observations of convectively-generated gravity 
XHANKINSON ET AL.: GRAVITY WAVES GENERATED BY CONVECTION DURING TWP-ICE, PART I.

40 Observational studies of convectively-generated waves have been based principally on ${ }_{41}$ radars [e.g. Sato et al., 1995; Dhaka et al., 2005], aircraft [e.g. Alexander et al., 2000], ${ }_{42}$ satellites [e.g. Hecht et al., 2009, using airglow imagery] and radiosondes [Karoly et al., ${ }_{43}$ 1996; Lane et al., 2003; Gong and Geller, 2010; Ki and Chun, 2011]. The work described ${ }_{44}$ here is based mostly on radiosonde observations from the Tropical Warm Pool Interna${ }_{45}$ tional Cloud Experiment (TWP-ICE), which took place in Darwin, Australia (near $130^{\circ} \mathrm{E}$, ${ }_{46} 12^{\circ} \mathrm{S}$ ) from 17 January to 13 February, 2006. (See Figure 1 for the location of TWPICE ${ }_{47}$ domain.) The campaign experiment is described in detail by May et al. [2008].

48

There are many studies that have used the observations taken during TWP-ICE, in50 cluding a few focused principally on gravity waves. Using radiosonde observations, Evan ${ }_{51}$ and Alexander [2008] identified inertia-gravity waves with periods of about 2 days during ${ }_{52}$ the suppressed monsoon period, which coincided with the end of the easterly phase of the ${ }_{53}$ quasi-biennial oscillation. These waves propagated to the south-east and had vertical and ${ }_{54}$ horizontal wavelengths around $6 \mathrm{~km}$ and 5500-7000 km respectively. Evan et al. [2012] ${ }_{55}$ extended this work using the European Centre for Medium-Range Weather Forecasts ${ }_{56}$ (ECMWF) operational analyses and the Weather Research and Forecasting model. Their ${ }_{57}$ simulation is consistent with the observations by [Evan and Alexander, 2008] and indicates ${ }_{58}$ that these waves originated from deep convection in the Indonesian region. Using satellite 59 imagery, Hecht et al. [2009] found waves (during the suppressed monsoon period) at an 60 altitude near $40 \mathrm{~km}$ with horizontal wavelengths between 200 and $400 \mathrm{~km}$. Furthermore, ${ }_{61}$ Hecht et al. [2009] identified two groups of waves at $80 \mathrm{~km}$ altitude in air glow images ${ }_{62}$ taken in the Alice Spring area: the first group had periods of 1 to 2 hours whereas the 
HANKINSON ET AL.: GRAVITY WAVES GENERATED BY CONVECTION DURING TWP-ICE, PARX F. 5

63 second group had periods of 15 to 25 minutes and horizontal wavelengths of 30 to $40 \mathrm{~km}$.

${ }_{64}$ This second group of waves were thought to have been generated by convection within a

${ }_{65}$ mesoscale system located between Darwin and Alice Springs.

67

The main goal of the present work is to deduce the properties of convectively-generated 
XHAGNKINSON ET AL.: GRAVITY WAVES GENERATED BY CONVECTION DURING TWP-ICE, PART I.

${ }_{85}$ are reported in Section 3. Our conclusions are given in Section 4.

\section{Data}

The data to be analyzed are summarized now.

\subsection{Profiles from the variational analysis during TWP-ICE}

The profiles constructed by a variational analysis from the observations taken during

s9 the TWP-ICE campaign [Xie et al., 2010] are used to define the mean state of the at-

${ }_{90}$ mosphere. The variational analysis, which is an objective analysis method, follows the ${ }_{91}$ method developed by Zhang and Lin [1997] to derive profiles of large-scale variables from ${ }_{92}$ a small network of sounding stations. The essence of this variational analysis method is 93 to make small perturbations to the observed profiles of temperature, wind and humidity

${ }_{94}$ while conserving column-integrated mass, moisture, energy, and momentum. The varia${ }_{95}$ tional analysis is constrained by the domain-averaged surface and top-of-the-atmosphere ${ }_{96}$ observations (e.g., radiative and heat fluxes and precipitation). Initial analyses of temper97 ature, wind and humidity are required for the variational analysis. These are generated 98 from TWP-ICE soundings using the interpolation scheme described by Cressman [1959] ${ }_{99}$ with the background from the ECMWF analyses. The profiles from the variational analysis represent the time-evolving conditions averaged over a $2 \times 2$ degree box centered on are identified with perturbations from this mean state. 
HANKINSON ET AL.: GRAVITY WAVES GENERATED BY CONVECTION DURING TWP-ICE, PAR $\bar{X}$ F. 7 
XHASNKINSON ET AL.: GRAVITY WAVES GENERATED BY CONVECTION DURING TWP-ICE, PART I.

${ }_{126}$ Since perturbations in the troposphere contain signals from processes other than gravity 
HANKINSON ET AL.: GRAVITY WAVES GENERATED BY CONVECTION DURING TWP-ICE, PAR F F. 9

149 is defined by a polynomial fitted to each vertical profile using least squares. The different

Figure 3 shows the time-height evolution of the horizontal wind perturbations at Point Stuart. The evolution of the temperature perturbations (not shown) is similar to that of zonal wind with an amplitude of about $10 \mathrm{~K}$. In Fig. 3, the phase propagation of $u^{\prime}$ and $v^{\prime}$ is downward (marked by arrows), which is one of the properties of upward propagating gravity waves [e.g. Andrews et al., 1987]. Figure 3 appears to show two distinct regimes with different phase speeds (given by the slope of the phase lines). The gravity waves in each regime will be analyzed separately. Note, these wave regimes are different from the meteorological regimes marked in Fig. 2.

In the first regime (Regime 1, 28 January - 6 February), large amplitude perturbations (around $8-20 \mathrm{~m} \mathrm{~s}^{-1}$ ) with clearly descending phase propagation are evident in the 22-28 $\mathrm{km}$ altitude range. The perturbations during this regime appear to be consistent with the 2-day inertia-gravity wave identified by Evan and Alexander [2008]. Waves in this 
XHAIIOKINSON ET AL.: GRAVITY WAVES GENERATED BY CONVECTION DURING TWP-ICE, PART I.

${ }_{172}$ regime are referred to as group L hereafter (where L stands for Long vertical wavelength).

174 identified by May et al. [2008].

175

\subsection{Convective activity estimated from satellite}


HANKINSON ET AL.: GRAVITY WAVES GENERATED BY CONVECTION DURING TWP-ICE, PAXT-I11

${ }_{193}$ is less than $1^{\circ} \mathrm{C}$. The estimates of convective activity are used to study the tropospheric sources the gravity waves.

\section{Inertia-Gravity Waves}


XHAIIKINSON ET AL.: GRAVITY WAVES GENERATED BY CONVECTION DURING TWP-ICE, PART I.

${ }_{215} 3$ hours. The quadrature spectra during the two regimes show clear differences. During ${ }_{216}$ Regime 1, the quadrature spectrum for waves of group L peaks at a ground-based period ${ }_{217}$ of 2.28 days and vertical wavelength of $5.2 \mathrm{~km}$ (left panel). During Regime 2, waves of ${ }_{218}$ group S have a ground-based period near 3.5 days and the vertical wavelengths in the ${ }_{219}$ range of 1.5 to $2.1 \mathrm{~km}$ (right panel). The properties of waves of groups $\mathrm{L}$ and $\mathrm{S}$ noted

226 during both regimes.

227

228

The process by which the frequency and horizontal and vertical wave numbers of the inertia-gravity waves are identified in the radiosonde soundings is as follows. First, the perturbations of the horizontal wind components and temperature are filtered (using a Fourier transform) to retain the frequencies with the peak powers indicated by the frequency-vertical wavenumber spectral analysis. For waves of groups L and S, the bandpass windows are between 1.7 and 3.3 days and 2.3 to 3.6 days, respectively. Second, the spectral Stokes parameter method developed by Eckermann and Vincent [1989] is used to determine the polarization ellipses (Section 3.1). A brief description of the Stokes parameter method is included in Appendix A. 
HANKINSON ET AL.: GRAVITY WAVES GENERATED BY CONVECTION DURING TWP-ICE, PAXT-I13

\subsection{Polarization ellipses from the Stokes parameter method}

$$
\Theta_{T_{+90}^{\prime}}=\tan ^{-1}\left(\frac{\overline{u^{\prime} T_{+90}^{\prime}}}{\overline{\overline{v^{\prime} T_{+90}^{\prime}}}}\right)
$$


XHAIXKINSON ET AL.: GRAVITY WAVES GENERATED BY CONVECTION DURING TWP-ICE, PART I.

257

${ }_{258}$ where $\Theta_{T_{+90}^{\prime}}$ is the angle between the wave propagation direction and the eastward hori${ }_{259}$ zontal axis and $T_{+90}^{\prime}$ is the value of the temperature perturbation after shifting the phase ${ }_{260}$ by $+90^{\circ}$ using a Hilbert transform. Although mixed Rossby-gravity waves also have

263

For waves of group L, the mean horizontal wave direction $\Theta$ estimated by the orientation of the polarization ellipses is -40.2 degrees, i.e. towards the south-east, with standard deviation of 12.8 degrees. Using Eq. 1 gives a similar direction, -51.3 degrees on average, with standard deviation of 7.8. The degree of polarization $d$ is high (0.96 on average) indicating that the signal is dominated by coherent waves rather than noise. The ratio of the minor to major axes of the ellipse $r$, which is related to the ratio of the inertial frequency $f$ to the intrinsic frequency of the waves $\omega_{*}$ (see Eq. 3 in Section 3.2), has a mean of 0.63 and standard deviation of 0.12 .

The waves comprising group S are less polarized than group L, with $d=0.74$ (on average). The propagation direction is more southward (see Fig. 5a and b), with the averages of $\Theta$ and $\Theta_{\left(T_{+90}^{\prime}\right)}$ being -72.2 and -66.0 degrees, respectively. For these waves, the standard deviation (among the stations) of the propagation direction $\Theta$ is relatively large (25.4 degrees), whereas $\Theta_{\left(T_{+90}^{\prime}\right)}$ has a much smaller standard deviation (3.4 degrees). The polarization ellipses for waves of group $\mathrm{S}$ have relatively large ratios $r$ (0.82 on average), 
${ }_{279}$ indicating that the intrinsic frequencies are low.

Following Eckermann [1996], the Stokes parameters are used to also determine the ver-

\subsection{Estimation of inertia-gravity wave properties}

When the effects of a linear vertical wind shear and the variation of density with height are taken into account, the dispersion relation of inertia-gravity waves is

$$
\omega_{*}^{2}=f^{2}+\frac{N^{2} k_{h}^{2}}{m^{2}+1 /\left(4 H_{s}^{2}\right)}-\frac{2 f k_{h} m \overline{V_{z}}}{m^{2}+1 /\left(4 H_{s}^{2}\right)}
$$

287

288

For inertia-gravity waves, the horizontal wind perturbation vectors rotate with height and their hodographs describe polarization ellipses with the major axis parallel to the 
wavenumber vector. The ratio of minor axis to the major axis $\mathrm{r}$ is

$$
r=\frac{f}{\omega_{*}}-\frac{k_{h} m \overline{V_{z}}}{\left[m^{2}+1 /\left(4 H_{s}^{2}\right)\right] \omega} .
$$

Equations 2 and 3 are then used to form the equation for $\omega_{*}$ :

$$
\omega_{*}^{2}\left(r^{2}-a^{2}\right)-2 \omega_{*} f r\left(1-a^{2}\right)+f^{2}\left(1-a^{2}\right)=0
$$

where $a^{2}=\frac{V_{z}^{2}}{N^{2}\left[1+\left(4 m^{2} H_{s}^{2}\right)^{-1}\right]}$. As shown by Hines [1989], the background wind shear may induce an additional ellipticity to the vertical profiles of horizontal wind perturbations, making quasi-stationary gravity waves to appear to have longer periods. Thus, the intrinsic period $\omega_{*}$ is taken as the root of Eq. 4 corresponding to the larger frequency (shorter periods), in which case

$$
\frac{\omega_{*}}{f}=\frac{r\left(1-a^{2}\right)+\left[r^{2}\left(1-a^{2}\right)^{2}-\left(r^{2}-a^{2}\right)\left(1-a^{2}\right)\right]^{1 / 2}}{r^{2}-a^{2}} .
$$

Given $\omega_{*}$ and $m$, the dispersion relation (Eq. 2) can be rearranged to give the horizontal wavenumber, in which case

$$
k_{\text {disp }}=\frac{f m \overline{V_{z}}}{N^{2}} \pm \frac{1}{N}\left[\frac{f^{2} m^{2}}{N^{2}}{\overline{V_{z}}}^{2}+\left(\omega_{*}^{2}-f^{2}\right)\left(m^{2}+\frac{1}{4 H_{s}^{2}}\right)\right]^{1 / 2}
$$

where $\mathrm{k}_{\text {disp }}$ takes the positive values in the wave propagation direction, which was estimated earlier by the Stokes parameter method. Note that as $H_{s} \rightarrow \infty$ Eqs. 2, 5 and 6 reduce to Eqs. 3, 5 and 6 in Cho [1995]. 
HANKINSON ET AL.: GRAVITY WAVES GENERATED BY CONVECTION DURING TWP-ICE, PAXT-I17

$$
k_{\text {dopp }}=\frac{\omega-\omega_{*}}{\bar{U}}
$$

301

${ }_{302}$ Here $\bar{U}$ is the mean horizontal wind component in the direction of wave propagation.

303 
XHAIISINSON ET AL.: GRAVITY WAVES GENERATED BY CONVECTION DURING TWP-ICE, PART I.

${ }_{319}$ relation (using Eq. 6). In this case, the horizontal wavelengths are smaller with the 320 average values of $3300 \mathrm{~km}$ and $2100 \mathrm{~km}$ for groups L and $\mathrm{S}$ respectively. Although the ${ }_{321}$ same order of magnitude, the horizontal wavelengths calculated using Eqs. 6 and 7 are 322 different. This difference arises from the inclusion of vertical wind shear in Eq. 6, as 323 well as the uncertainties in estimating vertical wavenumber $m$ in Eq. 6 and ground-based 324 frequency $\omega$ in Eq. 7 from discrete spectral analysis. Of these, the uncertainties in $m$ 325 and $\omega$ explain most of the difference; at low wavenumbers the uncertainty can be as large 326 as $100 \%$. The effects of the vertical wind shear on the estimates of wave properties are ${ }_{327}$ relatively small (less than $2 \%$ ) for group $\mathrm{L}$ (with $\overline{V_{z}} \approx-0.5 \mathrm{~m} \mathrm{~s}^{-1} \mathrm{~km}^{-1}$ ). In the layer ${ }_{328}$ below $22 \mathrm{~km}$, where the mean vertical wind shear is around $2 \mathrm{~m} \mathrm{~s}^{-1} \mathrm{~km}^{-1}$, the effects of ${ }_{329}$ the vertical wind shear on group $\mathrm{S}$ are larger $(5 \%$ for $\omega$ and $16 \%$ for $k)$. Although $H_{s}(\approx$ $\left.{ }_{330} 6 \mathrm{~km}\right)$ is comparable to $\lambda_{z}(\approx 5.2 \mathrm{~km})$, taking the limit as $H_{s} \rightarrow \infty$ in Eqs. 2 and 3 only 331 affects the result by less than $0.05 \%$.

\subsection{Ray tracing}

Wave groups L and S are further investigated by backward ray-tracing to understand 
HANKINSON ET AL.: GRAVITY WAVES GENERATED BY CONVECTION DURING TWP-ICE, PAXT-I19

${ }_{341} 10 \%$ in a $1^{o} \times 1^{o}$ box centered at the middle of the section. In the case of long sections,

343

\section{Conclusions}


XHA20KINSON ET AL.: GRAVITY WAVES GENERATED BY CONVECTION DURING TWP-ICE, PART I.

${ }_{363}$ of group $\mathrm{S}$ were detected in the lower layer of the stratosphere (in the 17.5-22 km layer)

364 with an intrinsic period near 45 hours. These waves had vertical wavelengths of $2-4 \mathrm{~km}$,

365 horizontal wavelengths of 2000-4000 km, and intrinsic periods near 45 hours. The hori-

${ }_{366}$ zontal propagation direction was from north-north-west and the vertical group velocity is upward, indicating the energy source of these waves is in the troposphere.

Backward ray tracing was employed to identify the potential sources of the groups.

\section{Appendix A: Stokes parameter method}

Stokes parameters are calculated using the formulation of Eckermann and Vincent [1989]. These parameters are

$$
\begin{aligned}
& \tilde{I}(m)=A\left(\overline{U_{R}^{2}(m)}+\overline{U_{I}^{2}(m)}+\overline{V_{R}^{2}(m)}+\overline{V_{I}^{2}(m)}\right) \\
& \tilde{D}(m)=A\left(\overline{U_{R}^{2}(m)}+\overline{U_{I}^{2}(m)}-\overline{V_{R}^{2}(m)}-\overline{V_{I}^{2}(m)}\right) \\
& \tilde{P}(m)=\quad 2 A\left(\overline{U_{R}(m) V_{R}(m)}+\overline{U_{I}(m) V_{I}(m)}\right) \\
& \tilde{Q}(m)=\quad 2 A\left(\overline{U_{R}(m) V_{I}(m)}-\overline{U_{I}(m) V_{R}(m)}\right)
\end{aligned}
$$

where $\mathrm{m}$ is the vertical wavenumber, $\mathrm{A}$ is a constant, and the subscripts $R$ and $I$ denote 
HANKINSON ET AL.: GRAVITY WAVES GENERATED BY CONVECTION DURING TWP-ICE, PAXT-I21

${ }_{381}$ the real and imaginary parts of the Fourier transforms of the vertical perturbation profiles

${ }_{382}$ of u' and v'. The overbars denote the average of all profiles available during each regime.

звз The Stokes parameters are evaluated for a given vertical wavenumber band by integrating

${ }_{384}$ in wavenumber space according to the expression

$$
X_{m 1, m 2}=\int_{m_{1}}^{m_{2}} \tilde{X}(m) d m
$$

385

${ }_{386}$ where $X_{m_{1}, m_{2}}$ is one of the Stokes parameters in (A1) evaluated over a wavenumber band ${ }_{387}$ between $m_{1}$ and $m_{2}$.

The properties of the polarization ellipses are then evaluated as

$$
\begin{aligned}
d & =\frac{\left(D^{2}+P^{2}+Q^{2}\right)^{1 / 2}}{I} \\
\Theta & =\frac{1}{2} \tan ^{-1}\left(\frac{P}{D}\right) \\
\delta & =\frac{1}{2} \tan ^{-1}\left(\frac{Q}{P}\right) \\
R & =\tan \left[\frac{1}{2} \sin ^{-1}\left(\frac{Q}{d I}\right)\right]
\end{aligned}
$$

where $d$ is the degree of polarization, $\Theta$ is the angle of the major axis counter-clockwise from the eastward direction; $\delta$ is the phase difference between $u^{\prime}$ and $v^{\prime}$ components, and $R$ is the ratio between the major to the minor axes of the ellipse.

393

Following Eckermann [1996], clockwise (CW) and anticlockwise (ACW) rotation of the horizontal wind perturbations with height can be determined from Stokes parameters as

396 follows 


$$
\begin{aligned}
C \tilde{W}(m) & =0.5[\tilde{I}(m)-\tilde{Q}(m)] \\
A \tilde{C} W(m) & =0.5[\tilde{I}(m)+\tilde{Q}(m)] .
\end{aligned}
$$

\section{Appendix B: Hodograph rotation for Mixed Rossby-Gravity waves} plane linearized about a basic state at rest and with constant Brunt-Vaisala frequency $N$.

The solution the horizontal velocity in a Mixed Rossby-Gravity wave is

$$
\left(u^{\prime}, v^{\prime}\right)=\hat{v}_{0} \omega y \exp \left(\frac{-\beta|m| y^{2}}{2 N}\right) \cos (m z)\left(-\frac{|m|}{N} \sin (k x-\omega t), \cos (k x-\omega t)\right)
$$

with dispersion relation

$$
m=-\operatorname{sgn}(\omega)(\beta+\omega k) \frac{N}{\omega^{2}}
$$

Then

$$
u^{\prime 2}+\left(\frac{m \omega y}{N}\right)^{2} v^{\prime 2}=\left(\frac{\hat{v}_{0} m \omega y}{N} \cos (m z)\right)^{2} \exp \left(\frac{-\beta|m| y^{2}}{N}\right)
$$

402

which describes an ellipse aligned along the x-axis (the zonal direction) with the ratio of

${ }_{404}$ the minor to major axes is $r=(N / m \omega y)$ (provided $\left.y \neq 0\right)$, from which $\omega=N /(m r y)$. 
HANKINSON ET AL.: GRAVITY WAVES GENERATED BY CONVECTION DURING TWP-ICE, PAXT-I23

The angle with the $\mathrm{x}$-axis made by the horizontal wind vector $\left(u^{\prime}, v^{\prime}\right)$ is $\tan \Theta=$ $-\cot (k x-\omega t) /(|m| \omega y)$, and hence

$$
\frac{\partial \Theta}{\partial z}=-\frac{1}{|\omega| y}\left(\frac{N^{2}(\beta+\omega k)}{|m| \sin ^{2}(k x-\omega t)}\right)
$$

406

\section{Notes}

1. Additional ray-tracing tests are performed with the ERAI data averaged over the periods of Regimes 1 and 2 in order to remove the long-period waves from the mean environment. The results are similar to the case with 6 -hourly data and are not shown here for brevity.

\section{References}


XHA2AKINSON ET AL.: GRAVITY WAVES GENERATED BY CONVECTION DURING TWP-ICE, PART I.

${ }_{421}$ Andrews, D., J. R. Holton, and C. B. Leovy, Middle Atmosphere Dynamics, pp 429 pp., Academic Press, 1987.

Beres, J. H., M. J. Alexander, and J. Holton, Effects of tropospheric wind shear on the spectrum of convectively generated gravity waves, J. Atmos. Sci., 59, 1805-1824, 2002.

Bretherton, C. S., Group velocity and the linear response of stratified fluids to internal heat or mass sources, J. Atmos. Sci., 45, 81-93, 1988.

Cho, J. Y. N., Inertio-gravity wave parameter estimation from cross-spectral analysis, $J$. Geophys. Res., 100(D9), 727-18, 1995.

Clark, T. L., T. Hauf, and J. P. Kuettner, Convectively forced internal gravity waves: Results from two-dimensional numerical experiments, Quart. J. Roy. Meteorol. Soc., 112, 899-925, 1986.

Cressman, G., An operational objective analysis scheme, Mon. Weather Rev., 87, 367-374, 1959.

Dhaka, S. K., M. K. Yamamoto, Y. Shibagaki, H. Hashiguchi, M. Yamamoto, and S. Fukao, Convection-induced gravity waves observed by the equatorial atmosphere radar $\left(0.2^{\circ} \mathrm{S}, 100.32^{\circ} \mathrm{E}\right)$ in Indonesia, Geophys. Res. Lett., 32, L14,820, doi:10.1029/2005GL022,907.2, 2005.

Eckermann, S. D., Hodographic analysis of gravity waves: relationships among Stokes parameters, rotary spectra and cross-spectral methods, J. Geophys. Res., 101, 169-19, 1996.

Eckermann, S. D., and R. A. Vincent, Falling sphere observations of anisotropic gravity wave motions in the upper stratosphere over Australia, Pure and Applied Geophysics PAGEOPH, 130, 509-532, 1989. 
HANKINSON ET AL.: GRAVITY WAVES GENERATED BY CONVECTION DURING TWP-ICE, PAXT-I25

${ }_{444}$ Evan, S., and M. J. Alexander, Intermediate-scale tropical Inertia gravity waves observed during the TWP-ICE campaign, J. Geophys. Res., 113, D14,101, doi:10.1029/2007JD009,289, 2008.

Evan, S., M. J. Alexander, and J. Dudhia, Model study of intermediate-scale tropical inertia-gravity waves in comparison to TWP-ICE campaign observations, J. Atmos. Sci., 69, 591-610, 2012.

Fovell, F., D. Durran, and J. R. Holton, Numerical simulation of convectively generated stratospheric gravity waves, J. Atmos. Sci., 49, 1427-1442, 1992.

Geller, M. A., and J. Gong, Gravity wave kinetic, potential, and vertical fluctuation energies as indicators of different frequency gravity waves, J. Geophys. Res., 115, D11,111,doi:10.1029/2009JD012,266, 2010.

Gong, J., and M. Geller, Vertical fluctuation energy in United States high vertical resolution radiosonde data as an indicator of convective gravity, J. Geophys. Res., 115, D11,110,doi:10.1029/2009JD012,265, 2010.

Grimsdell, A., M. J. Alexander, P. T. May, and L. Hoffmann, Model study of waves generated by convection with direct validation via satellite, J. Atmos. Sci., 67, 16171631, 2010.

H.-Y, C., and J.-J. Baik, Momentum flux by thermally induced internal gravity waves and its approximation for large-scale models, J. Atmos. Sci., 55, 3299-3310, 1998.

Hauf, T., and T. Clark, Three-dimensional numerical experiments on convectively forced internal gravity waves, Quart. J. Roy. Meteorol. Soc., 115, 309-333, 1989.

Hecht, J., et al., Imaging of atmospheric gravity waves in the stratosphere and upper mesosphere using satellite and ground-based observations over Australia during the 
XHA26KINSON ET AL.: GRAVITY WAVES GENERATED BY CONVECTION DURING TWP-ICE, PART I.

TWPICE campaign, J. Geophys. Res., 114, D18,123,doi:10.1029/2008JD011,259, 2009.

Hines, C. O., Tropopausal moutain waves over Arcibo: a case study, J. Atmos. Sci., 46, 476-488, 1989.

Inoue, T., A cloud type classification with NOAA 7 Split-window measurements, J. Geophys. Res., 92, 3991-4000, 1987.

Karoly, D. J., G. L. Roff, and M. J. Reeder, Gravity waves activity associated with tropical convection detected in TOGA COARE sounding data, Geophys. Res. Lett., 23, 261-264, 1996.

Ki, M.-O., and H.-Y. Chun, Inertia gravity waves associated with deep convection observed during the summers of 2005 and 2007 in Korea, J. Geophys. Res., 116, D16,122, 2011.

Lane, T. P., and M. W. Moncrieff, Stratospheric gravity waves generated by multiscale tropical convection., J. Atmos. Sci., 65, 2598-2614, 2008.

Lane, T. P., and M. J. Reeder, Convectively generated gravity waves and their effect on the cloud environment, J. Atmos. Sci., 58, 2427-2440, 2001a.

Lane, T. P., and M. J. Reeder, Modelling the generation of gravity waves by a maritime continent thunderstorm, Quart. J. Roy. Meteorol. Soc., 127, 2705-2724, 2001b.

Lane, T. P., M. J. Reeder, and T. L. Clark, Numerical modeling of gravity waves generation by deep tropical convection, J. Atmos. Sci., 58, 1249-1274, 2001.

Lane, T. P., M. J. Reeder, and F. M. Guest, Convectively generated gravity waves observed from radiosonde data taken during MCTEX, Quart. J. Roy. Meteorol. Soc., 129, D11,111, doi:10.1029/2009JD012,266, 2003.

Lin, Y.-L., R. L. Deal, and M. S. Kulie, Mechanisms of cell regeneration, development, and propagation within a two-dimensional multicell storm, J. Atmos. Sci., 55, 1867-1886, 
HANKINSON ET AL.: GRAVITY WAVES GENERATED BY CONVECTION DURING TWP-ICE, PAXT-I27 1998.

Marks, C. J., and S. D. Eckermann, A three-dimensional nonhydro-dynamic ray-tracing model for gravity waves: formulation and preliminary results for the middle atmosphere, J. Atmos. Sci., 52, 1959-1984, 1995.

May, P. T., J. H. Mather, G. Vaughan, C. Jakob, G. M. McFarquhar, K. N. Bower, and G. G. Mace, The tropical warm pool international cloud experiment, Bull. Amer. Meteorol. Soc., 89, 629-645, doi:10.1175/BAMS-89-5-629, 2008.

Pierce, A. D., and S. C. Coroniti, A mechanism for the generation of acoustic-gravity waves during thunderstorm formation., Nature, 210, 1209-1210, 1966.

Salby, M., and R. Garcia, Transient response to localized episodic heating in the tropics. Part I: Excitation and short-time near-field behavior, J. Atmos. Sci., 44, 458-498, 1987.

Sato, K., A statistical study of the structure, saturation and sources of inertio-gravity waves in the lower stratosphere observed with the MU radar, J. of Atmospheric and Solar-Terrestrial Physics, 56, 755-774, 1994.

Sato, K., H. Hashiguchi, and S. Fukao, Gravity waves and turbulence associated with cumulus convection observed with the UHF/VHF clear-air doppler radars, J. Geophys. Res., 100, 7111-7119, 1995.

Thompson, R. O. R. Y., Observation of inertial waves in the stratosphere, Quart. J. Roy. Meteorol. Soc., 104, 691-698, 1978.

Vincent, R. A., S. J. Allen, and S. D. Eckermann, Gravity-wave parameters in the lower stratosphere, in Gravity wave processes: Their parameterization in global climate models, edited by K. Hamilton, pp. 7-25, Springer, New York, 1997. 
X - 2\&ANKINSON ET AL.: GRAVITY WAVES GENERATED BY CONVECTION DURING TWP-ICE, PART I.

${ }_{512}$ Wada, K., T. Nitta, and K. Sato, Equatorial inertia-gravity waves in the lower stratosphere revealed by TOGA-COARSE IOP data, J. Met. Soc. Japan, 77, 721-736, 1999. 
HANKINSON ET AL:: GRAVITY WAVES GENERATED BY CONVECTION DURING TWP-ICE, PART IX - 29

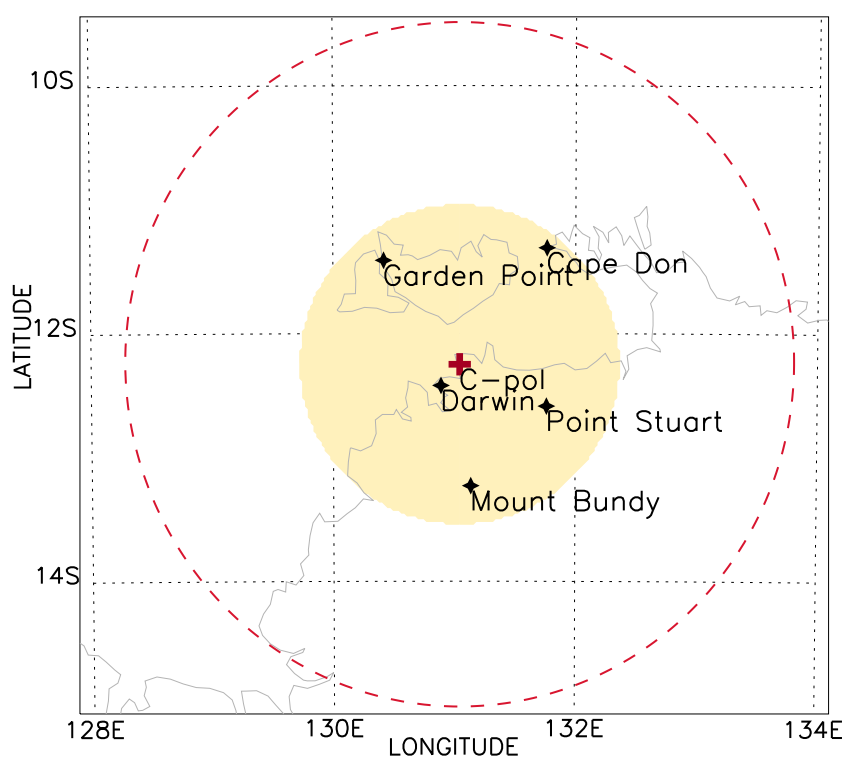

Figure 1. Observation sites during TWPICE. The shaded region centered at the cross sign marks the area covered by the $\mathrm{C}$-pol radar data. The dashed circle shows the $300 \mathrm{~km}$ radius from the radar center. 
(a)

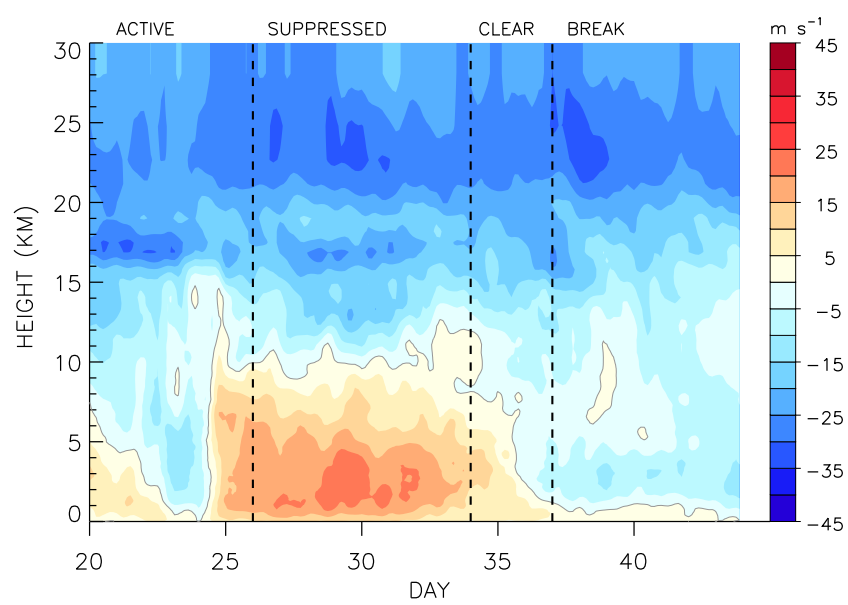

(b)

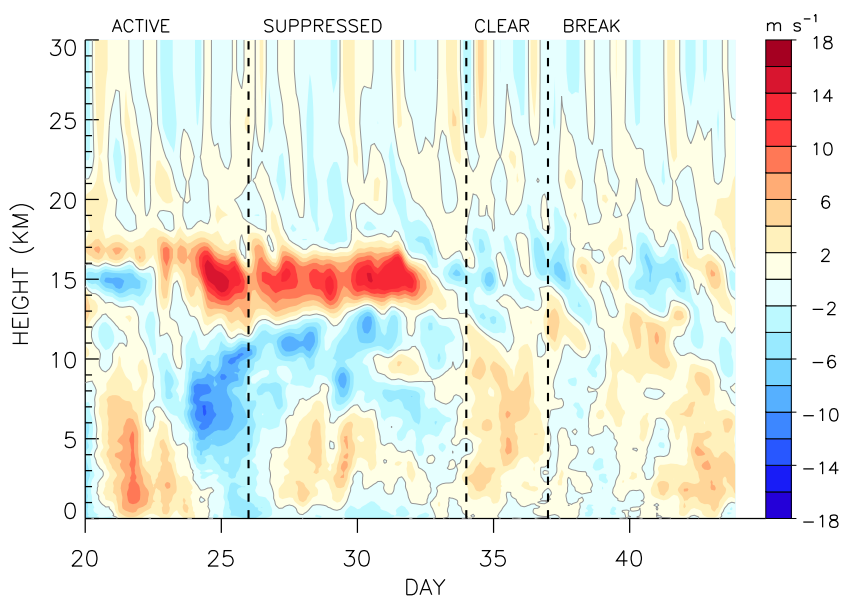

Figure 2. Time-height evolution of the mean (a) zonal and (b) meridional wind components provided by the variational analysis [Xie et al., 2010]. The horizontal axis denotes day number in year 2006.

(a)

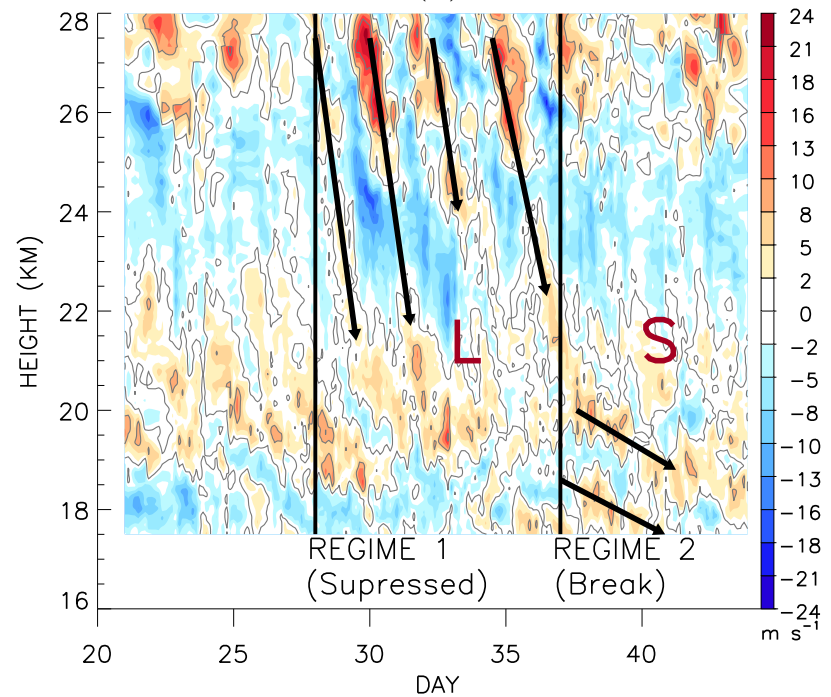

(b)

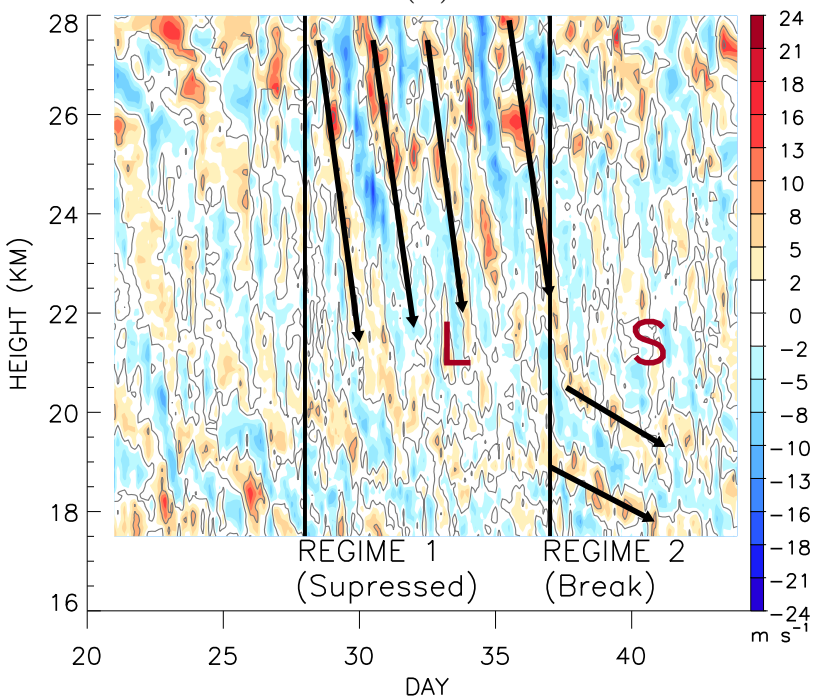

Figure 3. Time-height evolution of the zonal (a) and meridional (b) wind perturbations at the station Point Stuart. Positive values are contoured. The mean state is taken from the variational analysis. Arrows mark the descending phase propagation. 
(a)

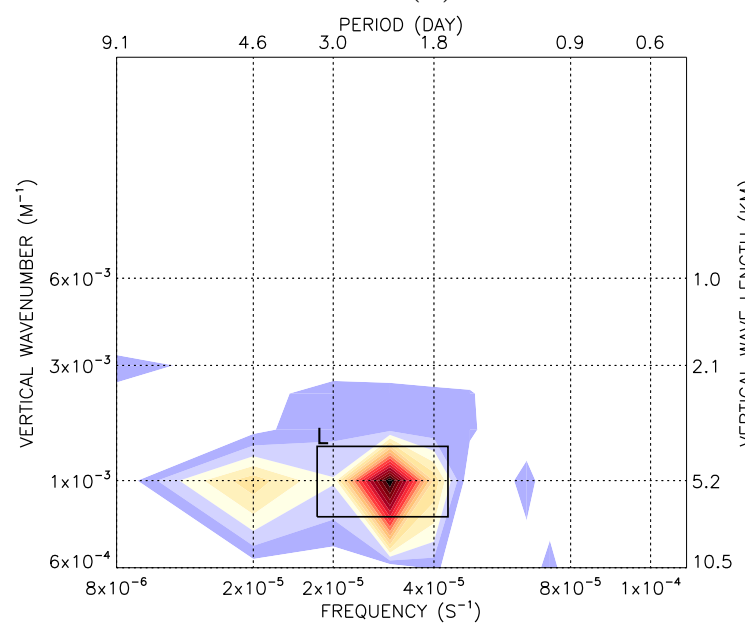

(b)

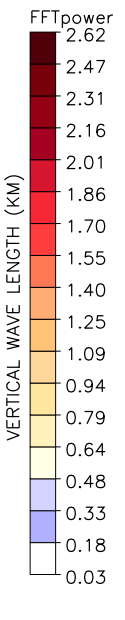

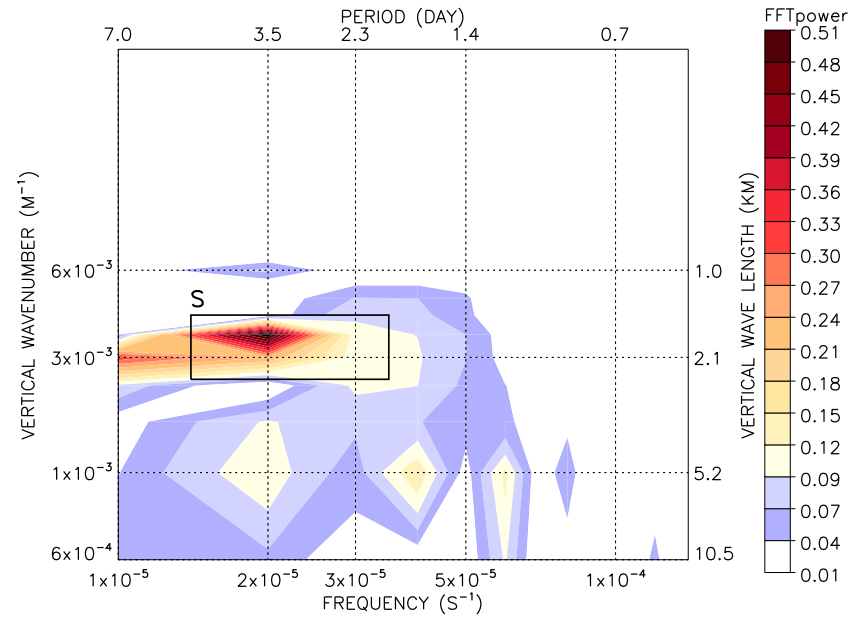

Figure 4. Two-dimensional quadrature spectra of the horizontal wind perturbations for Regime 1 (left) and Regime 2 (right).

(a)

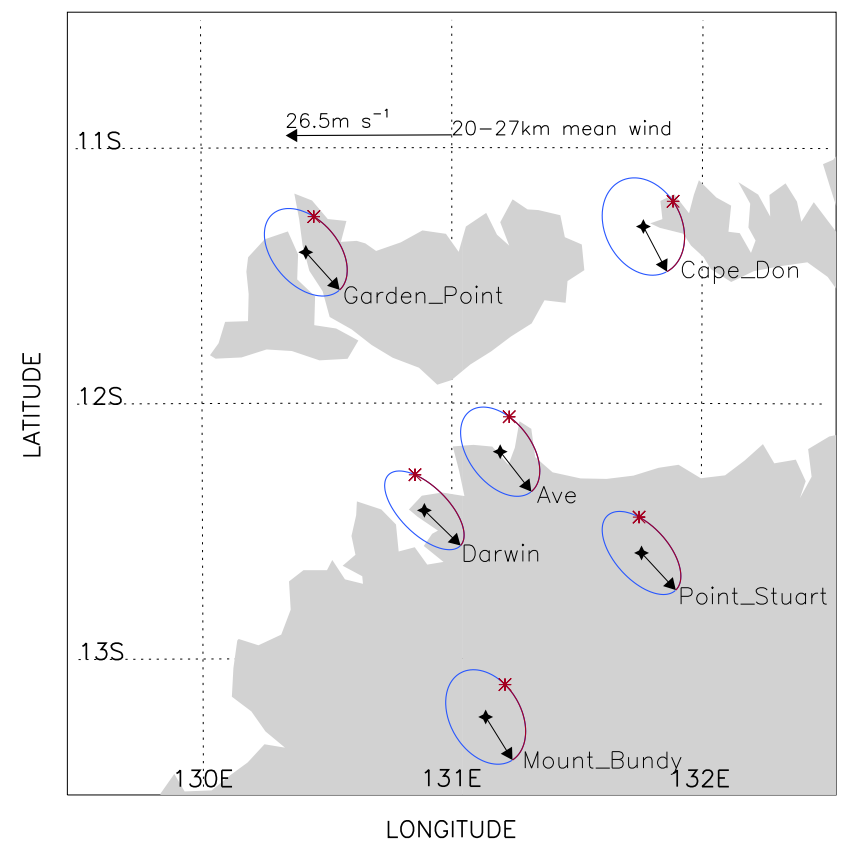

(b)

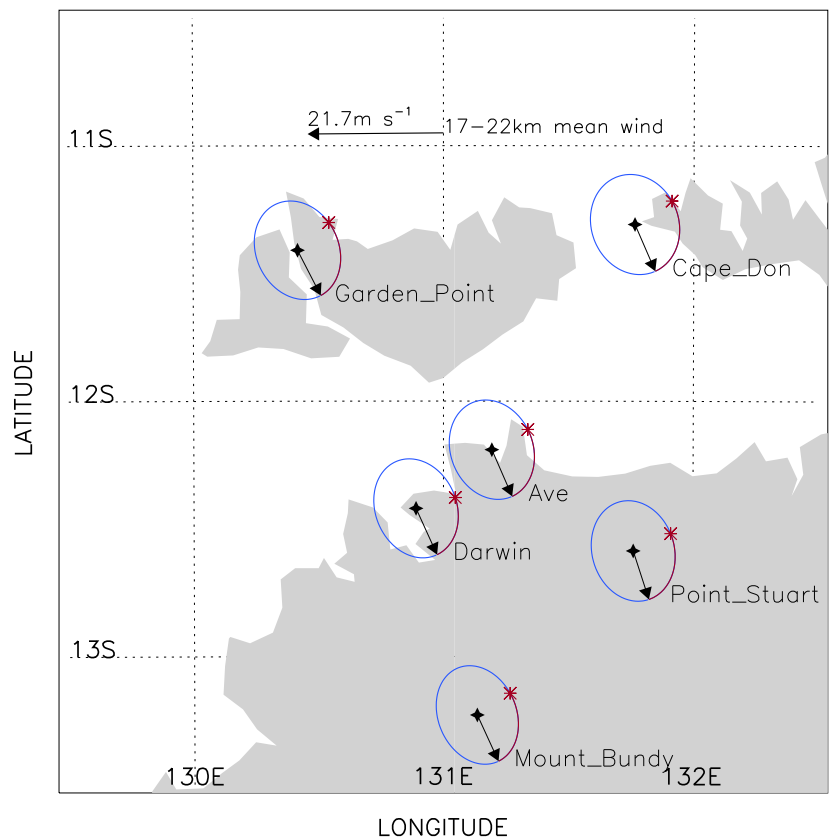

Figure 5. Polarization ellipses calculated using the Stokes parameter method for waves of group L (a) and S (b). Arrows point in the direction of the horizontal wave vectors. Phase differences $\delta$ between v' and u' are shown by the arcs (red in the online version) starting from the heads of the vectors to the points marked by ${ }^{*}$ sign. 
Table 1. Gravity wave properties calculated using Stokes parameters for waves WL and WS. $\mathrm{ACW} / \mathrm{CW}$ is the ratio between anti-clockwise and clockwise rotating power spectra, signifying the ratio between upward and downward energy propagations. $\bar{U}$ is the wind in the direction of the horizontal wave vector averaged over the duration and height range of each wave. $\tau$ and $\tau_{*}$ are the ground-based and intrinsic wave periods, respectively. $\lambda_{z}$ is the vertical wavelength. $\lambda_{\text {disp }}$ and $\lambda_{\text {dopp }}$ are the horizontal wavelengths calculated from the dispersion relation (Eq. 6) and the doppler relation (Eq. 7), respectively.

\begin{tabular}{|c|c|c|c|c|c|c|c|c|c|c|}
\hline \multirow[b]{2}{*}{ Station } & \multicolumn{10}{|c|}{$\operatorname{group~L~}\left(\lambda_{z} \approx 5.2 \mathrm{~km}, \tau \approx 60 \mathrm{~h}, \overline{V_{z}} \approx-0.5 \mathrm{~m} \mathrm{~s}^{-1} \mathrm{~km}^{-1}, 22-28 \mathrm{~km}\right)$} \\
\hline & $\mathrm{d}$ & $\begin{array}{c}\delta \\
(\operatorname{deg})\end{array}$ & $\begin{array}{c}\Theta \\
(\operatorname{deg})\end{array}$ & $\begin{array}{c}\Theta_{\left(T_{+90}^{\prime}\right)} \\
(\mathrm{deg})\end{array}$ & $r$ & $\begin{array}{c}\mathrm{ACW} / \\
\mathrm{CW}\end{array}$ & $\begin{array}{c}\bar{U} \\
\left(\mathrm{~m} \mathrm{~s}^{-1}\right)\end{array}$ & $\begin{array}{c}\tau_{*} \\
(\mathrm{~h})\end{array}$ & $\begin{array}{l}\lambda_{\text {disp }} \\
(\mathrm{km})\end{array}$ & $\begin{array}{l}\lambda_{\text {dopp }} \\
(\mathrm{km})\end{array}$ \\
\hline Cape Don & 0.96 & 99.2 & -18.2 & -61.7 & 0.76 & 26.8 & -12.6 & 43.3 & 4547 & 7025 \\
\hline Darwin & 0.97 & 128.6 & -50.1 & -43.6 & 0.48 & 7.2 & -19.2 & 26.6 & 2122 & 3310 \\
\hline Garden Point & 0.98 & 114.3 & -46.6 & -47.6 & 0.65 & 17.2 & -17.9 & 36.5 & 3308 & 5991 \\
\hline Mount Bundy & 0.95 & 109.4 & -45.7 & -57.4 & 0.71 & 18.8 & -14.3 & 40.0 & 3816 & 6171 \\
\hline Point Stuart & 0.94 & 123.7 & -40.6 & -46.4 & 0.53 & 8.2 & -18.3 & 29.8 & 2461 & 3906 \\
\hline Average & 0.96 & 115.0 & -40.2 & -51.3 & 0.63 & 15.6 & -16.6 & 35.2 & 3263 & $\overline{5280}$ \\
\hline Stdev & 0.01 & 11.6 & 12.8 & 7.8 & 0.12 & 8.1 & 2.9 & 7.0 & 997 & 1590 \\
\hline & \multicolumn{10}{|c|}{$\operatorname{group} \mathrm{S}\left(\lambda_{z} \approx 1.8 \mathrm{~km}, \tau \approx 70.8 \mathrm{~h}, \overline{V_{z}} \approx 2 \mathrm{~m} \mathrm{~s}^{-1} \mathrm{~km}^{-1}, 17.5-22 \mathrm{~km}\right)$} \\
\hline Cape Don & 0.68 & 97.1 & -59.2 & -66.0 & 0.87 & 5.08 & -9.0 & 48.1 & 2568 & 4828 \\
\hline Darwin & 0.73 & 82.3 & -109.5 & -65.1 & 0.81 & 5.97 & -9.3 & 44.3 & 1999 & 3949 \\
\hline Garden Point & 0.67 & 101.2 & -40.6 & -62.4 & 0.82 & 4.83 & -10.2 & 45.1 & 2090 & 4542 \\
\hline Mount Bundy & 0.85 & 96.2 & -77.1 & -64.8 & 0.78 & 10.33 & -9.4 & 42.6 & 1817 & 3622 \\
\hline Point Stuart & 0.76 & 95.8 & -74.6 & -71.5 & 0.82 & 6.88 & -7.0 & 45.1 & 2100 & 3129 \\
\hline Average & 0.74 & 94.5 & -72.2 & -66.0 & 0.82 & 6.62 & -9.0 & 45.0 & 2115 & 4014 \\
\hline Stdev & 0.07 & 7.1 & 25.4 & 3.4 & 0.03 & 2.23 & 1.2 & 2.0 & 278 & 686 \\
\hline
\end{tabular}


(a) Group L

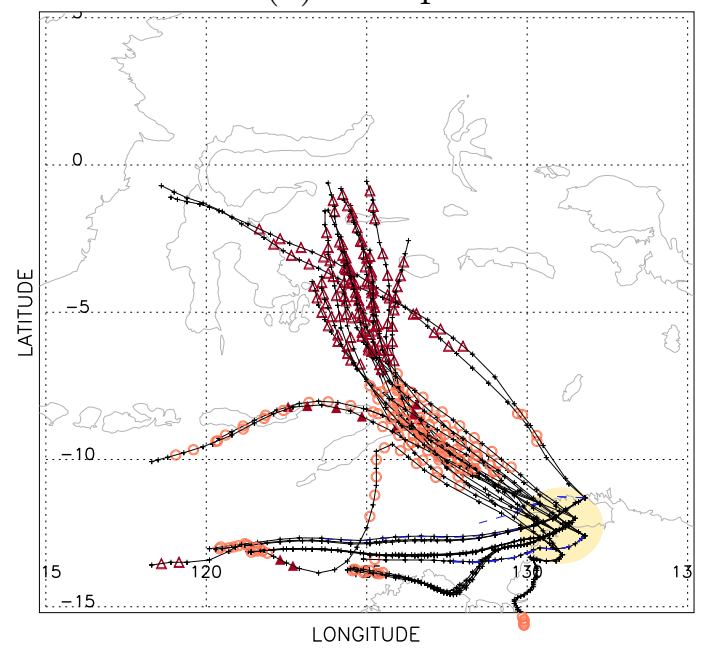

(c)

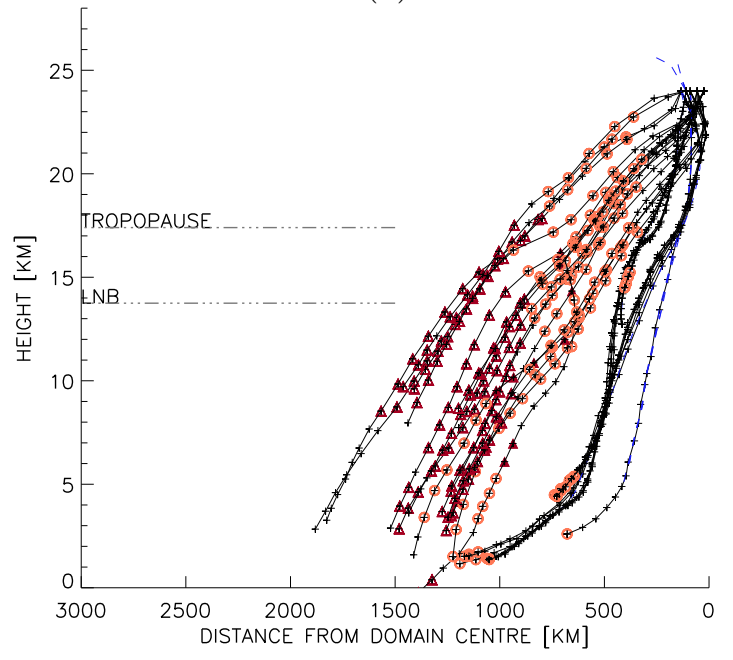

(b) Group S

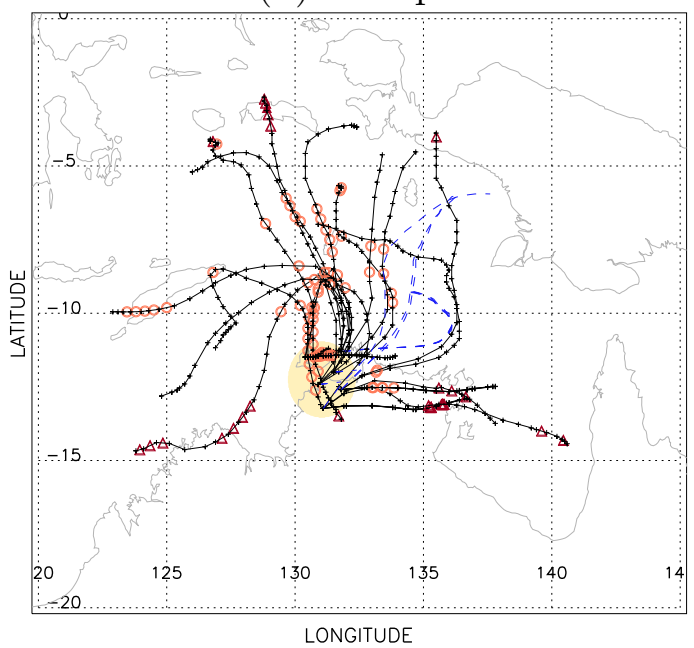

(d)

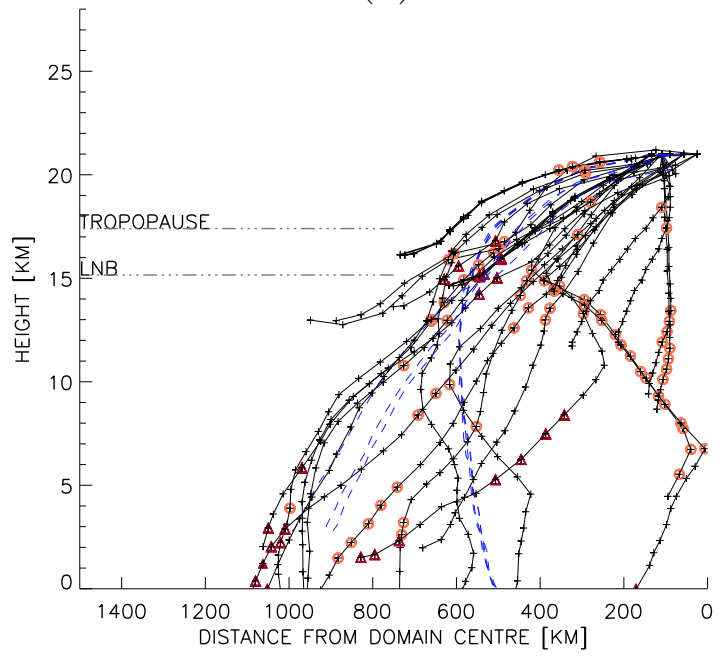

Figure 6. Backward ray-tracing for groups L (left panels, rays arriving at 00Z 04/02/2006) and S (right panels, rays arriving on 00Z 08/02/2006). (a,b) Horizontal plane view; (c,d) distanceheight view. Black solid (dashed blue) lines show rays that do (do not) pass over regions with convective activity of deep (red triangles) and/or shallow (brown circles) convection. Shaded areas in a and b show the radar coverage during TWPICE. Distance is calculated from the location of C-Pol radar at (131.044 E,12.249 S). 


\section{Gravity Waves Generated by Convection during TWP-ICE. Part II: High-Frequency Gravity Waves}

Mai C. N. Hankinson, ${ }^{1}$ M. J. Reeder, ${ }^{1}$ and T. P. Lane ${ }^{2}$

Mai C.N. Hankinson, School of Mathematical Sciences, Monash University, Wellington Road, Melbourne, Victoria 3800, AUSTRALIA. (Mai.C.Nguyen@monash.edu)

M. J. Reeder, School of Mathematical Sciences and ARC Centre for Excellence for Climate System Science, Monash University, Wellington Road, Melbourne, Victoria 3800, AUSTRALIA. (Michael.Reeder@monash.edu)

T. P. Lane, School of Earth Sciences and ARC Centre of Excellence for Climate System Science, The University of Melbourne, Victoria 3010, AUSTRALIA. (tplane@unimelb.edu.au)

${ }^{1}$ School of Mathematical Sciences,

Monash University, Melbourne, Victoria, AUSTRALIA.

${ }^{2}$ School of Earth Sciences, The University of Melbourne, Victoria, AUSTRALIA. 
3 Abstract.

${ }_{4} \quad$ High-frequency gravity waves are analyzed using radiosonde soundings taken

${ }_{5}$ during the Tropical Warm Pool - International Cloud Experiment (TWP-

- ICE) campaign. The intrinsic periods of these waves are estimated to be be-

7 tween 20-40 minutes. The high-frequency wave activity in the stratosphere,

s defined by mass-weighted variance of the vertical motion of the sonde, has

9 a maximum following the afternoon local convection indicating that these

${ }_{10}$ waves are generated by local convection. The wave activity is strongest in

${ }_{11}$ the lower stratosphere below $22 \mathrm{~km}$ and, during the suppressed monsoon pe-

12 riod, is modulated with a 3-4-day period. The concentration of the wave ac-

${ }_{13}$ tivity in the lower stratosphere is consistent with the properties of the en-

${ }_{14}$ vironment in which these waves propagate, whereas its 3-4-day modulation

${ }_{15}$ is explained by the variation of the convection activity in the TWP-ICE do-

16 main. At low rainfall intensity $\left(<1 \mathrm{~mm} \mathrm{hr}^{-1}\right)$, the wave activity increases as

${ }_{17}$ rainfall intensity increases. At high values of rainfall intensity, however, the

${ }_{18}$ wave activity associated with deep convective clouds is independent of the

19 rainfall intensity. 


\section{Introduction}

39 Radiosonde data are available globally and for long times, but they are limited by rel40 atively coarse time resolution (typically 3 to 12 hours between two consecutive obser${ }_{41}$ vations). Moreover, the vertical wavelengths cannot be calculated from the sounding 
XHANKINSON ET AL.: GRAVITY WAVES GENERATED BY CONVECTION DURING TWP-ICE, PART II.

${ }_{42}$ directly [Reeder et al., 1999; Lane et al., 2003]. For all these reasons, there is a need for

${ }_{43}$ detailed observation of high-frequency gravity waves. Such observations are required to

${ }_{44}$ validate model studies and parameterization schemes [e.g. Chun and Baik, 1998; Beres

${ }_{45}$ et al., 2002]. The main aspects of the high-frequency gravity waves addressed here include

${ }_{46}$ their vertical and temporal variations, and their relationship with the rain rate, which is

${ }_{47}$ a proxy for the diabatic heating rate.

48

49 The remainder of the paper is organized as follows. The observations and data analysis ${ }_{50}$ are described in Section 2. The properties of the high-frequency gravity waves (including ${ }_{51}$ their periods, vertical and horizontal wavelengths) are analyzed in Section 3. The temporal ${ }_{52}$ and vertical variations in the wave activity and its relationship with the rain rate are ${ }_{53}$ presented in Section 4. Section 5 explains the observed variations of the wave activity ${ }_{54}$ by examining the properties of the environment for wave propagation and the variation ${ }_{55}$ of the convective sources in the vicinity of TWPICE. Finally, conclusions are given in ${ }_{56} \quad$ Section 6.

\section{Data}

${ }_{57}$ The radiosonde data taken during TWPICE have been described in Part I and, hence,

${ }_{58}$ are not repeated here. Figure 1, showing the locations of the observation stations dur${ }_{59}$ ing TWP-ICE, is reprinted here for convenience. As in Part I, two weather regimes are ${ }_{60}$ analyzed separately. Regime 1 is the period from 28 January to 6 February 2006 char${ }_{61}$ acterized by a suppressed monsoon, while Regime 2 is the monsoon break from 7 to 13 ${ }_{62}$ February 2006. The remainder of this section describes the calculation of the vertical 
${ }_{63}$ velocity perturbations, from which the properties of the high-frequency gravity waves are deduced, and the radar and satellite data used to define the convective activity.

\subsection{Perturbations of vertical velocity derived from radiosonde soundings}

Properties of the high-frequency gravity waves are derived from perturbations in the

${ }_{66}$ ascent rate of the balloon using the method described by Lane et al. [2003], Gong and

${ }_{67}$ Geller [2010], and Geller and Gong [2010]. The ascent rate of the balloon is calculated

${ }_{68}$ from the time derivative of the altitude of the balloon, which is itself determined using

${ }_{69}$ the hypsometric equation. The wave perturbations of vertical velocity $w^{\prime}$ are defined as

70 the deviations from the background ascent rate. The assumption underpinning the anal-

${ }_{71}$ ysis is that these perturbations in the ascent rate are a result of high-frequency gravity

72 waves. The perturbations are obtained by first fitting and then subtracting a polynomial

${ }_{73}$ from each vertical profile of the ascent rate. Since perturbations in the troposphere con-

74 tain signals from processes other than gravity waves such as turbulence and convection,

75 the analysis of the gravity waves is carried out in the stratosphere from 17.5 to $28 \mathrm{~km}$

76 (the tropopause is located near $17 \mathrm{~km}$ during the campaign). The perturbations in the

77 stratosphere are calculated as departures from a cubic polynomial, though the order of

78 the polynomial does not affect the results qualitatively (as will be discussed in Section

79 4.1). In addition, perturbations of vertical velocity in the troposphere (examined between

so 3 and $10 \mathrm{~km}$ ) are used in Section 4.2 to relate the wave activity of high-frequency gravity waves in the stratosphere with its possible source of tropospheric convective activity. For

${ }_{82}$ the troposphere, the perturbations are calculated by removing a linear least-square fit ${ }_{83}$ to the vertical profile. The linear fit is chosen here rather than a high-order polynomial 
XHAOKINSON ET AL.: GRAVITY WAVES GENERATED BY CONVECTION DURING TWP-ICE, PART II.

${ }_{84}$ because of the ambiguities introduced by convective clouds.

\subsection{Precipitation estimates from radar}

${ }_{86}$ Precipitation estimates from C-pol radar (the description of which can be found in ${ }_{87}$ Keenan et al. [1998]) are available every 10 minutes on a $2.5 \times 2.5 \mathrm{~km}$ grid. The area cov-

${ }_{88}$ ered by these data is shown as the shaded region in Figure 1. In addition to the rainfall s9 rates, rainfall type (either convective, stratiform or mixed), as determined by the method

${ }_{91}$ and area for each type are accumulated over the 3-hour periods prior to the observation

${ }_{92}$ times. These data will be used in Section 4 to relate the activity of high-frequency waves

${ }_{93}$ to the diabatic heating implied by the rainfall estimated from the C-pol radar.

\subsection{Convective activity estimated from satellite}

Infra-red measurements from the MTSAT satellite are used to quantify the convective

${ }_{96}$ activity in the areas surrounding the TWPICE domain to complement the radar obser-

${ }_{97}$ vations. Convection is identified by the method of Inoue [1987]. Deep convection is

98 assumed where the brightness temperature of the IR1 channel $(10.3-11.3 \mu \mathrm{m})$ is lower

${ }_{99}$ than a threshold value IR $1_{t o p}$, which signifies that the cloud top is above the middle troposphere, and the difference between channels IR1 and IR2 $(11.5-12.5 \mu \mathrm{m})$ is less than $0.5^{\circ} \mathrm{C}$. IR $1_{\text {top }}$ is chosen to be $-10^{\circ} \mathrm{C}$ which is above the $500 \mathrm{hPa}$ level for TWPICE. Shallow convection is identified when the brightness temperature on channel IR1 lies between IR $1_{\text {top }}$ and $2^{\circ} \mathrm{C}$, and the (IR1-IR2) difference in the brightness temperatures is less than 


\section{Properties of High-Frequency Gravity Waves}

\subsection{Frequency}

115

$$
b\left(\frac{N^{2}}{\omega_{*}^{2}}\right)^{2}-\left(\frac{b}{V / P}+1\right) \frac{N^{2}}{\omega_{*}^{2}}+1=0
$$

The intrinsic frequencies have also been calculated using the 1.7-day high-pass filtered temperature perturbations to eliminate the contributions from the low-frequency waves

$$
\text { August 14, 2013, 9:09am D R A F T }
$$


XHASKINSON ET AL.: GRAVITY WAVES GENERATED BY CONVECTION DURING TWP-ICE, PART II.

${ }_{123}$ (see Part I). The resultant frequencies have a mean of 24 minutes and a standard deviations

${ }_{124}$ of 6 minutes, which are relatively close to the estimates using the unfiltered perturbations.

${ }_{125}$ Thus, based on this analysis the mean intrinsic periods of the high-frequency gravity waves

${ }_{126}$ lay in the range 20 to 40 minutes.

\subsection{Vertical and horizontal wavelengths}




$$
\left|\frac{\lambda_{z}}{\lambda_{h}} \frac{\bar{U}}{\bar{W}}\right| \ll 1 \quad \text { and } \quad \frac{\lambda_{z}}{\tau \bar{W}} \ll 1
$$

\section{Properties of the wave activity}

\subsection{Vertical and temporal variation of the wave activity}


XHANKINSON ET AL.: GRAVITY WAVES GENERATED BY CONVECTION DURING TWP-ICE, PART II.

${ }_{162}$ but varies mostly with a 1-day period during Regime 2 . While the 1-day period variation

\subsection{Diurnal variation of the wave activity}


$\left.{ }_{184}+0930 \mathrm{hrs}\right)$ and the larger peak is in the early morning at $0630 \mathrm{LT}$. Regime 1 has a

The diurnal variation of $\overline{\rho w^{2}}$ in the troposphere $(3-10 \mathrm{~km})$ and lower stratosphere $(17.5-22 \mathrm{~km})$ are plotted also in Figure 4. While $\overline{\rho w^{\prime 2}}$ in the lower stratosphere largely represents the wave activity, its counterpart in the troposphere may include the effects of other processes such as turbulence and convection. In the troposphere, the maximum of $\overline{\rho w^{\prime 2}}$ occurs at $1530 \mathrm{LT}$, which is just prior to the afternoon precipitation maximum. In contrast, the early morning maximum in the precipitation at 0630 LT corresponds only to a weak increase in the tropospheric $\overline{\rho w^{\prime 2}}$. The wave activity in the stratosphere shows one peak at 1830-2130 LT, which lags the afternoon precipitation maximum by 3 hours. This lag in the stratospheric wave activity suggests that the gravity waves in the stratosphere are generated by convection in the troposphere. Nevertheless, the 3-hour lag should not 3 be viewed simply as the time taken for the gravity waves to propagate from troposphere 24 to the stratosphere as the time resolution of the data is 3 hours. Large values of $\overline{\rho w^{\prime 2}}$ in the troposphere are most likely attributable to turbulence and convection, which may 
XHANKINSON ET AL.: GRAVITY WAVES GENERATED BY CONVECTION DURING TWP-ICE, PART II.

${ }_{206}$ occur well before the generation of gravity waves.

The reason for the absence of a stratospheric maximum in the wave activity following the early morning precipitation maximum is examined now. Assuming that high-frequency

\subsection{Relationship of the wave activity with the rainfall intensity}


${ }_{228}$ Bretherton, 1988]. For this reason, the relationship between the stratospheric wave ac-

${ }_{229}$ tivity and the convective rainfall intensity, which is a proxy for the diabatic heating by

${ }_{230}$ convection, is examined now.

231

239 shallow.

240 
XHANKINSON ET AL.: GRAVITY WAVES GENERATED BY CONVECTION DURING TWP-ICE, PART II.

${ }_{250}$ with deep convection (marked by filled red triangles).

251

Differences in the wave activity in the lower and upper layers can be seen by comparing

${ }_{254}$ lower layer (panel a) of both shallow and deep convection types is much larger than that

\section{Modulation of the High-Frequency Wave Activity}

\subsection{Variation in the propagation properties of the medium}

The properties of the medium through which small-amplitude gravity waves propagate ${ }_{267}$ is characterized by the Scorer parameter $L^{2}$, which is defined by

$$
L^{2}=\frac{N^{2}}{(c-U)^{2}}+\frac{U_{z z}}{(c-U)}-\frac{1}{H_{s}} \frac{U_{z}}{(c-U)}-\frac{1}{4 H_{s}^{2}}
$$




$$
\frac{d^{2} \hat{w}}{d z^{2}}+\left(L^{2}-k_{h}^{2}\right) \hat{w}=0
$$

275 
XHANGINSON ET AL.: GRAVITY WAVES GENERATED BY CONVECTION DURING TWP-ICE, PART II.

289 speeds between -40 and $+40 \mathrm{~ms}^{-1}$ and in all directions. The results of these calculations

${ }_{290}$ for Regimes 1 and 2 in the layers 18-20 km and 24-26 km are shown in Figure 6. The wind

${ }_{291}$ and potential temperature profiles used to construct Figure 6 come from the variational

${ }_{292}$ analysis and are averaged for days 31-33 to represent Regime 1 and days 38-40 to rep-

${ }_{293}$ resent Regime 2. Waves propagating upward and downstream may reach critical levels,

${ }_{294}$ i.e., the level at which $c=U$. As a wave propagates upwards and approaches a critical

295 level, the ground-based frequency is conserved (provided the environment is stationary).

${ }_{296}$ The intrinsic frequency is doppler-shifted by the background wind to zero and the wave is

${ }_{297}$ either absorbed, reflected or partially transmitted depending on the details of the environ-

ment. Waves propagating upstream (to the east) require larger horizontal wavelengths to

${ }_{299}$ propagate vertically than those propagating downstream (in the absence of critical levels).

300

${ }_{301}$ The critical horizontal wavelength for the upper layer during Regime 1 , denoted $\lambda_{R 1 U}^{*}$, 302 is plotted as a function of ground-based phase speed in Figure 6a. In general, $\lambda^{*}$ increases ${ }_{303}$ as the phase speed in the zonal direction increases. Consequently, the horizontal wave304 length of upward propagation waves travelling to the west can be shorter than upward ${ }_{305}$ propagating waves traveling to the east. For example, $\lambda^{*}=12 \mathrm{~km}$ when the phase speed 306 is $20 \mathrm{~m} \mathrm{~s}^{-1}$ to the east whereas $\lambda^{*}=1 \mathrm{~km}$ when it is $20 \mathrm{~m} \mathrm{~s}^{-1}$ to the west.

Figures $6 \mathrm{~b}, \mathrm{c}$ and $\mathrm{d}$ show how $\lambda^{*}$ changes with layer and regime. The difference between

$\lambda_{R 1 U}^{*}$ (Figure 6a) and that in Regime 2, denoted $\lambda_{R 2 U}^{*}$, is plotted in Figure 6b. Likewise, the difference between $\lambda_{R 1 U}^{*}$ and $\lambda^{*}$ in the lower layer during Regime $1, \lambda_{R 1 L}^{*}$, is plotted in Figure 6c, while the difference between $\lambda_{R 1 U}^{*}$ and $\lambda^{*}$ in the lower layer in Regime $2, \lambda_{R 2 L}^{*}$, 
${ }_{312}$ is plotted in Figure 6d. $\lambda^{*}$ in the upper layer changes little from Regime 1 to Regime 2.

${ }_{313}$ In contrast, in the lower layer, $\lambda^{*}$ is much smaller during Regime 2 compared to Regime 1.

314 In other words, during Regime 2, the lower stratosphere is more favorable for the vertical

315 wave propagation of high-frequency gravity waves than during Regime 1. In addition, 316 negative differences (i.e. smaller $\lambda^{*}$ in the lower layer than in the upper layer) in panels 
XHAASKINSON ET AL.: GRAVITY WAVES GENERATED BY CONVECTION DURING TWP-ICE, PART II.

$33528 \mathrm{~km}$, and that this decrease is accompanied by an increase in the critical wavelength.

${ }_{336}$ This general pattern is not dependent on the choice of phase speed, and is consistent with

${ }_{337}$ the observed distribution of the high-frequency wave activity, which is concentrated in

338 the lower stratosphere below about $22 \mathrm{~km}$ (see Figure 2a). The largest contribution to

339 the Scorer parameter comes from the buoyancy term, which is of order $10^{-6} \mathrm{~m}^{-2}$. At a

${ }_{340}$ height of $20 \mathrm{~km}$, the curvature and shear terms are of order $10^{-7}-10^{-6}$ and $10^{-8} \mathrm{~m}^{-2}$,

${ }_{341}$ respectively, while at $24 \mathrm{~km}$, the curvature and shear terms are of order $10^{-12}$ and $10^{-9}$

${ }_{342} \mathrm{~m}^{-2}$, respectively. At times, the curvature term at $20 \mathrm{~km}$ makes a significant contribu-

tion, reaching the same order of magnitude as the buoyancy term, increasing the Scorer parameter and reducing the critical wavelength.

\subsection{Variation in the wave source}

Although the 3-4-day variation of the wave activity during Regime 1 appears in Figure 
${ }^{357}$ of deep convection using IR satellite imagery from MTSAT. The plotted rain rates are

358 averaged over the radar scan area, which is within $150 \mathrm{~km}$ radius from Darwin. The

359 3-4-day variation in the wave activity appears related to the variation in the area covered

${ }_{360}$ by deep convection within about $150-300 \mathrm{~km}$ of Darwin with peaks during days 31-33

361 and 35-36. Within a radius of $150 \mathrm{~km}$, the radar-derived rain rates and the area covered

${ }_{362}$ by deep convection show only the first peak. Hence, it seems likely that the second peak

${ }_{363}$ in the wave activity is generated by the convection outside of the area covered by the radar.

364

To test the possibility that some of the high-frequency gravity waves detected in the TWP-ICE radiosondes are generated outside of the area covered by the radar, rays are traced backwards in time using the code GROGRAT [Marks and Eckermann, 1995]. The wind and temperature fields used to define the environment come from the 6-hourly ERA ${ }_{369}$ Interim reanalysis. Ray tracing is done for waves with horizontal wavelengths of 7, 15, 25 
XHA2OKINSON ET AL.: GRAVITY WAVES GENERATED BY CONVECTION DURING TWP-ICE, PART II.

380 6-13 km layer in the middle troposphere was also identified by Ki and Chun [2011] as the

381 height range from which the convectively-generated gravity waves originated.) Thus, the

382 backward traced rays presented here support the possibility that the small peak in the

${ }_{383}$ wave activity on days 35-36 is related to the convection from outside of the TWP-ICE

${ }_{384}$ domain. In addition, most of rays traced backwards from the first peak during days 31-

33 (not shown) come from the area with deep convection within the TWP-ICE domain.

${ }_{386}$ These ray-tracing results are consistent with the concurrence of the peaks in the wave activity and the rain rates, and hence, supporting idea that the main contribution to the peak in the wave activity during days 31-33 comes from the convection within the domain.

As discussed by Berry et al. [2012], about half of the rainfall in the Australian sum1 mer monsoon is related to the passage of low-level, cyclonic potential vorticity anomalies.

${ }_{392}$ Figure 9 shows the time-latitude Hovmöller diagram of the potential vorticity in the layer ${ }_{393}$ between the $310-320 \mathrm{~K}$ isentropic surfaces. This layer is located near $700 \mathrm{hPa}$ level, at 394 which cyclonic PV is typically produced by tropical convection. The first and second peaks 395 in the wave activity correspond to the enhanced cyclonic potential vorticity (marked by ${ }_{396}$ letters $\mathrm{A}$ and $\mathrm{B}$, respectively, in Figure 9). In particular, the second peak is associated with the region of enhanced cyclonic potential vorticity which extends to the south of

Darwin. Thus, the periods of enhanced cyclonic potential vorticity are consistent with the convection coverage derived from satellite imagery. Moreover, it appears that the second peak was generated by the convection outside the area of TWP-ICE and that the 3-4 day variation in the wave activity reflects the temporal variation in cyclonic potential 
vorticity anomalies in the region and their associated convection.

\section{Conclusions}

The properties of high-frequency gravity waves were determined from the fluctuations in 
XHA22KINSON ET AL.: GRAVITY WAVES GENERATED BY CONVECTION DURING TWP-ICE, PART II.

${ }_{424}$ propagation properties of the medium and the time-variation of the wave source. It was

${ }_{425}$ found that the propagation properties (as measured by the Scorer parameter) of the layer

${ }_{426}$ between $22-26 \mathrm{~km}$ were not favorable for short waves propagating to the east (upstream).

${ }_{427}$ Thus, the presence of this layer was consistent with the decrease of the wave activity

${ }_{428}$ with height. The 3-4-day variation was found to be consistent with the variation of the convection activity in the region within $300 \mathrm{~km}$ of the TWP-ICE domain, which was also

${ }_{430}$ related to the variability in synoptic scale potential vorticity anomalies.

431

\section{References}

${ }_{437}$ Beres, J. H., M. J. Alexander, and J. Holton, Effects of tropospheric wind shear on the 
HANKINSON ET AL.: GRAVITY WAVES GENERATED BY CONVECTION DURING TWP-ICE, PABXI-IR3

Dhaka, S. K., M. K. Yamamoto, Y. Shibagaki, H. Hashiguchi, M. Yamamoto, and S. Fukao, Convection-induced gravity waves observed by the equatorial atmosphere radar $\left(0.2^{\circ} \mathrm{S}, 100.32^{\circ} \mathrm{E}\right)$ in Indonesia, Geophys. Res. Lett., 32, L14,820, doi:10.1029/2005GL022,907.2, 2005.

Gardener, C. S., and N. F. Gardener, Measurement distortion in aircraft, space shuttle, and balloon observations of atmospheric density and temperature perturbation spectra, J. Geophys. Res., 98, 1023-1033, 1993.

Geller, M. A., and J. Gong, Gravity wave kinetic, potential, and vertical fluctuation energies as indicators of different frequency gravity waves, J. Geophys. Res., 115, D11,111,doi:10.1029/2009JD012,266, 2010.

Gong, J., and M. Geller, Vertical fluctuation energy in United States high vertical resolution radiosonde data as an indicator of convective gravity, J. Geophys. Res., 115, D11,110,doi:10.1029/2009JD012,265, 2010.

Hecht, J., et al., Imaging of atmospheric gravity waves in the stratosphere and upper mesosphere using satellite and ground-based observations over Australia during the TWPICE campaign, J. Geophys. Res., 114, D18,123,doi:10.1029/2008JD011,259, 2009.

Inoue, T., A cloud type classification with NOAA 7 Split-window measurements, J. Geophys. Res., 92, 3991-4000, 1987.

Kaur, M., et al., Characteristics of Tropospheric Gravity Waves using the Equatorial Atmosphere Radar at Koto Tabang (0.20S, 100.32E), Indonesia during CPEA -2 campaign, Atmos. Res., 109-110, 84-94, 2012.

Keenan, T., K. Glasson, T. Cummings, J. Keeler, and J. Lutz, The BMRC/NCAR C-band polarimetric (C-pol) radar system, J. Atmos. Ocean Technol., 15, 871-886, 1998. 
XHA2AKINSON ET AL.: GRAVITY WAVES GENERATED BY CONVECTION DURING TWP-ICE, PART II.

${ }_{468}$ Ki, M.-O., and H.-Y. Chun, Inertia gravity waves associated with deep convection observed during the summers of 2005 and 2007 in Korea, J. Geophys. Res., 116, D16,122, 2011.

Lane, T. P., M. J. Reeder, and T. L. Clark, Numerical modeling of gravity waves generation by deep tropical convection, J. Atmos. Sci., 58, 1249-1274, 2001. 
HANKINSON ET AL.: GRAVITY WAVES GENERATED BY CONVECTION DURING TWP-ICE, PART IIX - 25

${ }_{491} \quad$ http://dx.doi.org/10.1016/j.jastp.2011.01.024, 2011.

${ }_{492}$ Vallgren, A., Statistical characteristics of convective storms in Darwin, northern Australia,

${ }_{493}$ Master's thesis, Lulea University of Technology, Sweden, 2006.

${ }_{494}$ Wapler, K., and T. P. Lane, A case of offshore convective initiation by interacting land $495 \quad$ breezes near Darwin, Australia, Meteorol. Atmos. Phys., 115, 123-137, 2012.

${ }_{496}$ Xie, S., T. Hume, C. Jakob, S. A. Klein, R. B. McCoy, and M. Zhang, Observed large-

${ }_{497}$ scale structures and diabatic heating and drying profiles during TWP-ICE, J. Climate, $498 \quad$ 23, 57-79, doi: 10.1175/2009JCLI3071.1, 2010. 


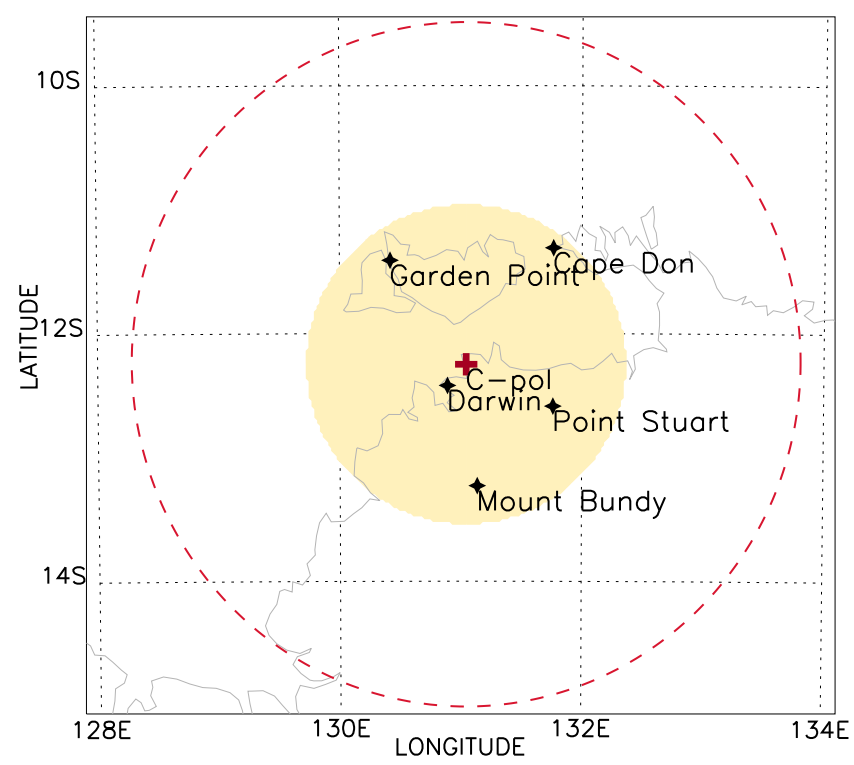

Figure 1. Observation sites during TWPICE. The shaded region centred at the cross sign marks the area covered by the $\mathrm{C}$-pol radar data. The dashed circle shows the $300 \mathrm{~km}$ radius from the radar centre. 
(a)

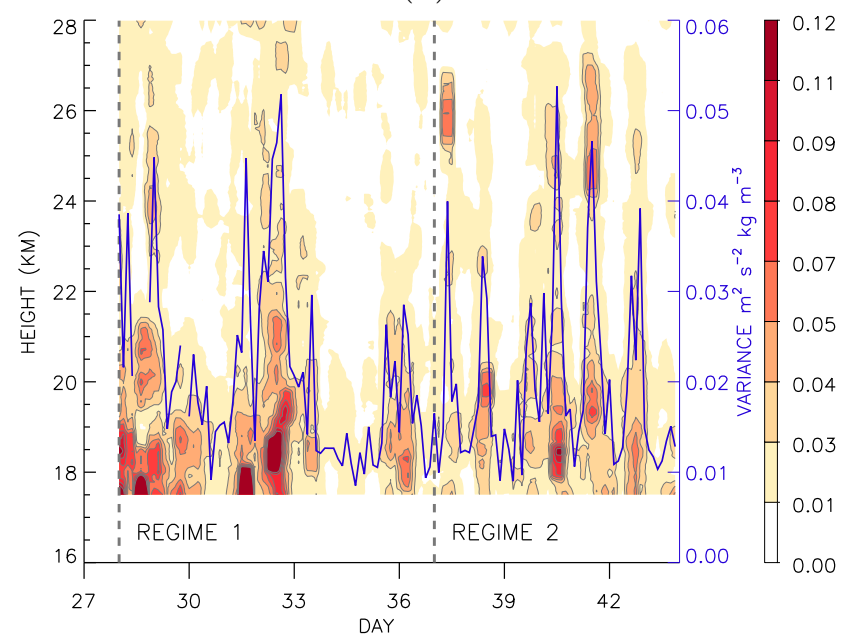

(b)

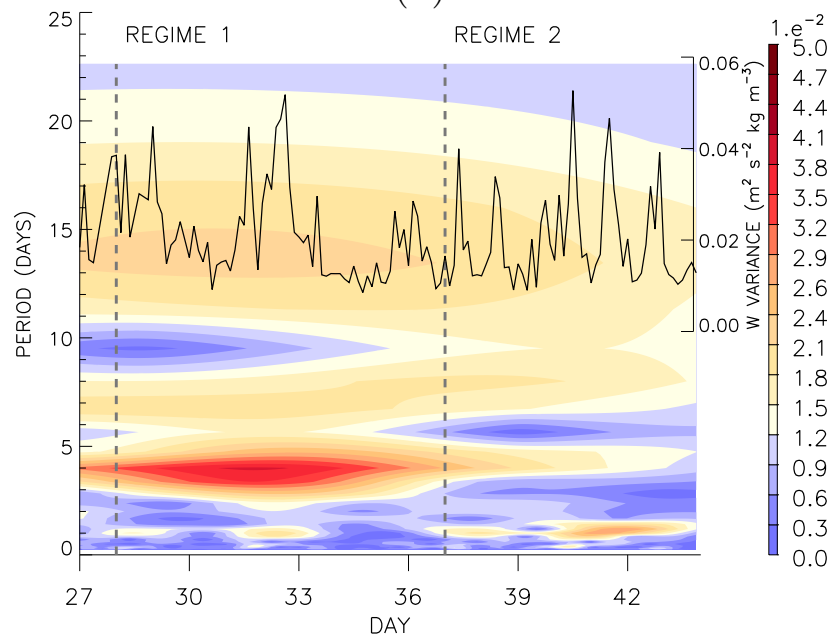

Figure 2. Evolution of high-frequency wave activity in the stratosphere. a) Time-height plot of $\rho w^{\prime 2}$ (shaded) and b) wavelet (Morlet) transform (shaded) of the mean wave activity $\overline{\rho w^{\prime 2}}$ (lines in both panels) in the stratosphere $(17.5-28 \mathrm{~km})$. 
(a)

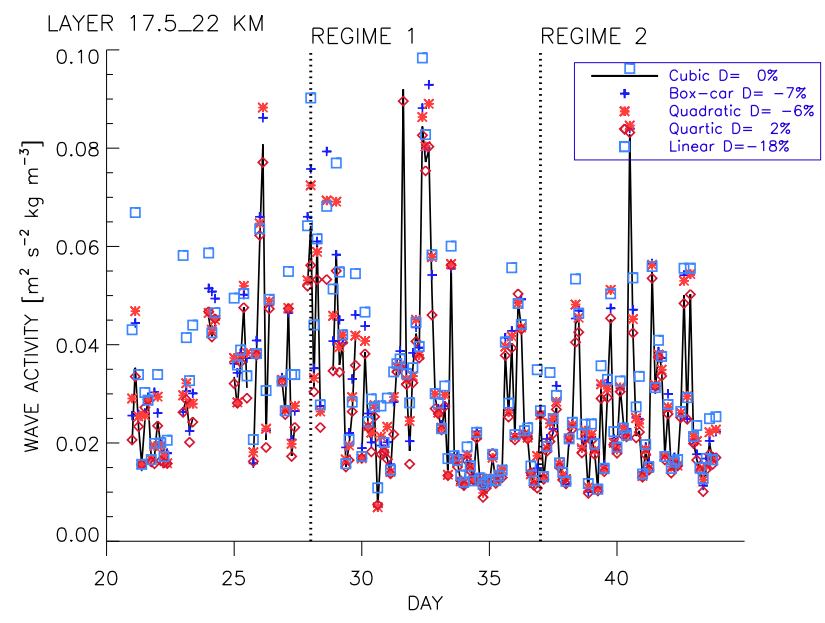

(b)

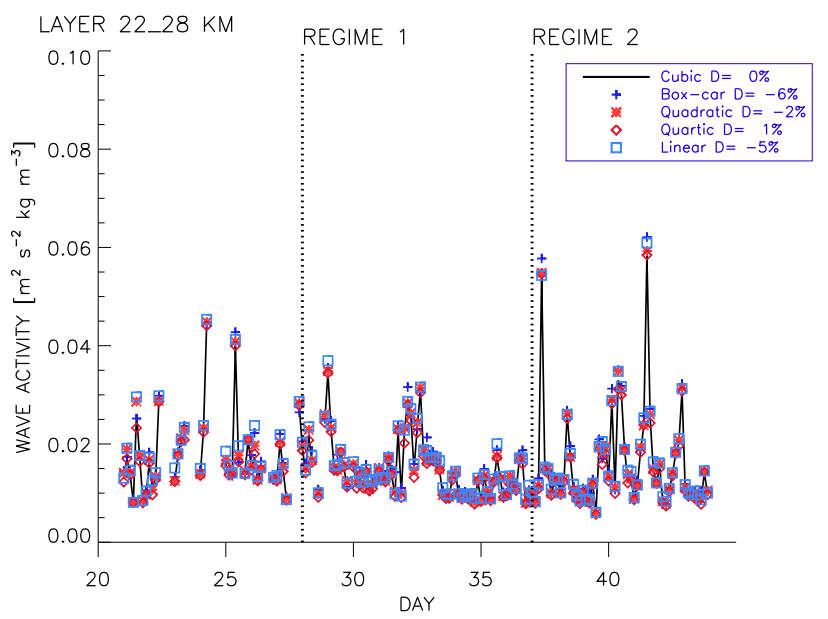

Figure 3. Variation of high-frequency wave activity in the stratosphere averaged for a) the 17.5$22 \mathrm{~km}$ layer, b) the $22-28 \mathrm{~km}$ layer. Perturbations of vertical velocity are calculated by removing fitted polynomials of first order (blue squares), second order (red asteriks), third order (solid line) and fourth order (red diamonds). Plus signs show the wave activity calculated by applying a 5-km box-car smoothing after a fitted cubic polynomial was removed from the vertical profiles of the balloon's ascent rates. $\mathrm{D}=<\left(\rho w_{\text {cubic }}^{\prime 2}-\rho w_{i}^{\prime 2}\right) / \rho w_{\text {cubic }}^{\prime 2}>$, where $i$ denotes the calculations with different base polynomials, $<>$ is the time average. 


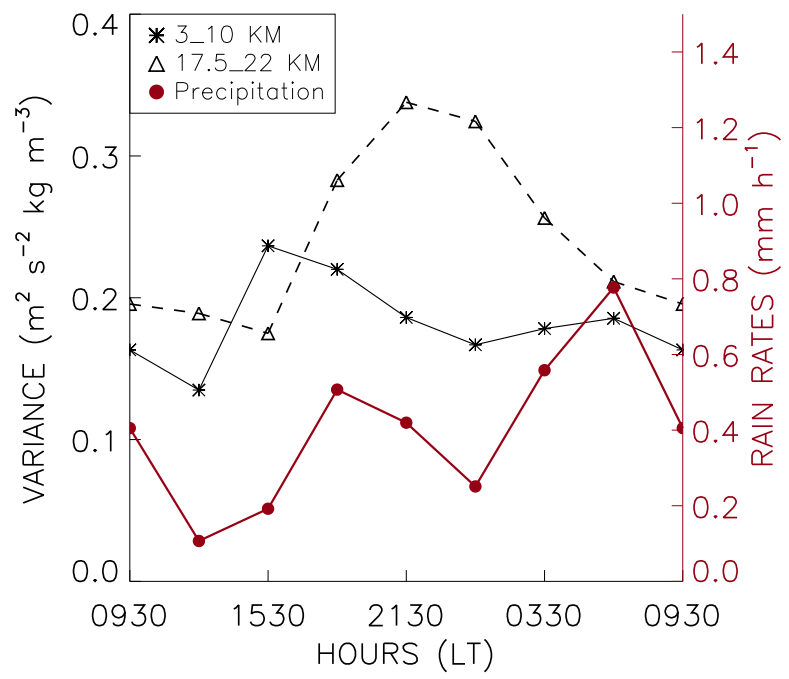

Figure 4. Diurnal variation of $\overline{\rho w^{\prime 2}}$ during Regime 2 in the lower stratosphere $17.5-22 \mathrm{~km}$ (dashed line with triangles), troposphere $3-10 \mathrm{~km}$ (solid line with stars), and of the area-averaged rain rates (red solid lines with circles). $\overline{\rho w^{\prime 2}}$ in the stratosphere is multiplied by 10 for clarity.

(a) $17.5-22 \mathrm{~km}$

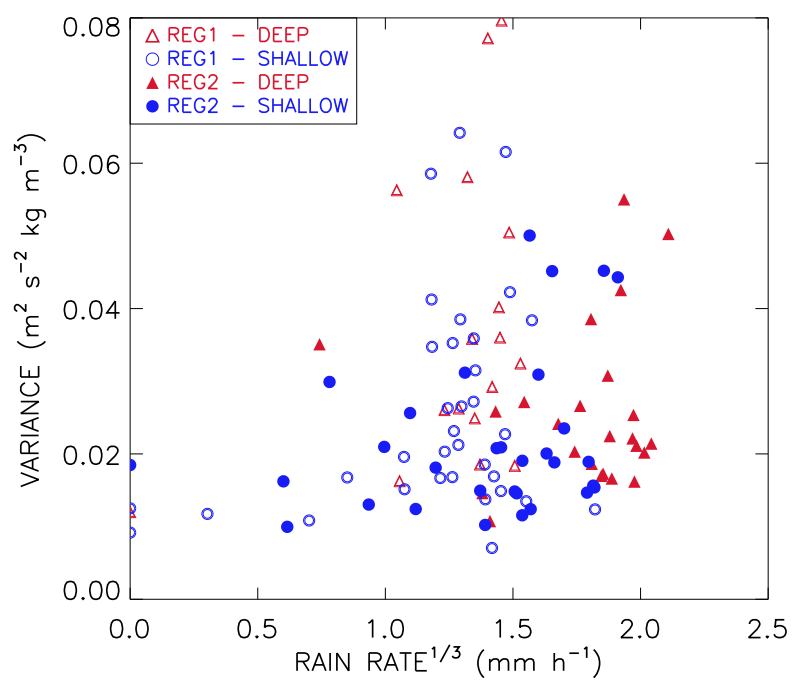

(b) $22-28 \mathrm{~km}$

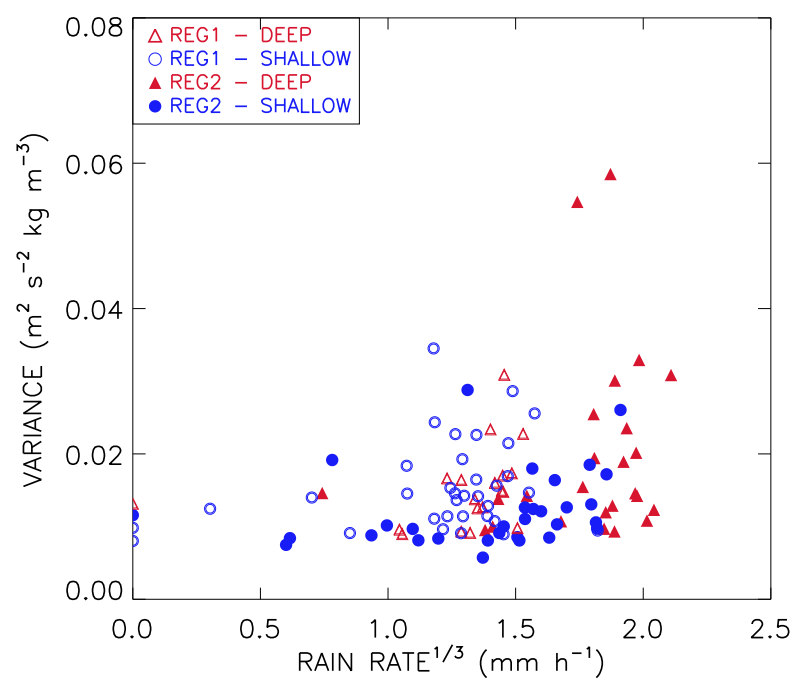

Figure 5. Scatter plot of $\overline{\rho w^{\prime 2}}$ during Regimes 1 and 2 in the layer (a) 17.5-22 km and (b) $22-28 \mathrm{~km}$ as a function of the cube root of the convective rainfall intensity. The open symbols are used for Regime 1 and the closed symbols used for Regime 2. 
(a) Regime 1

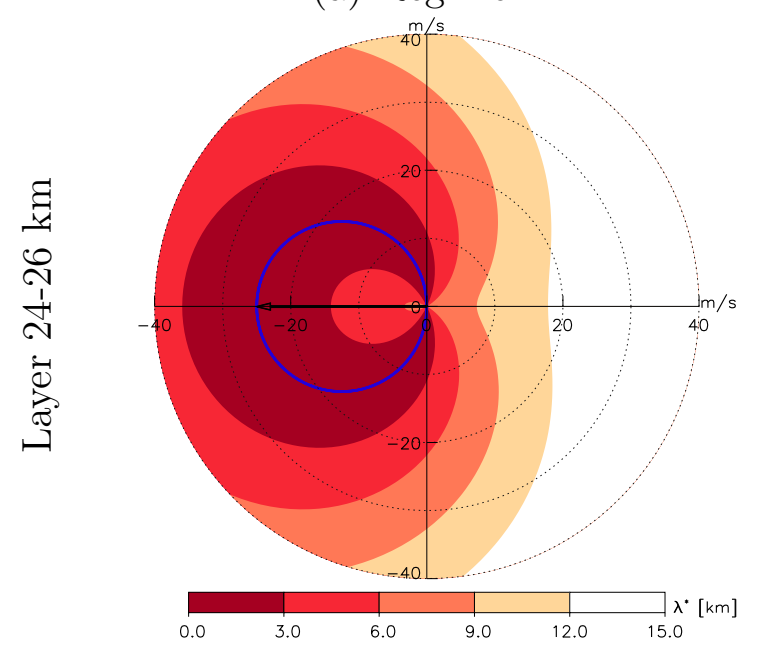

(c)

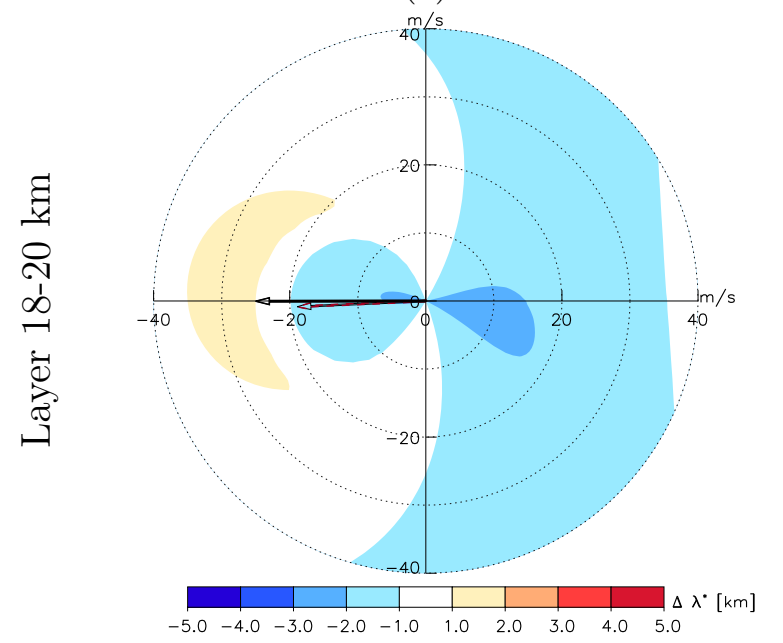

(b) Regime 2

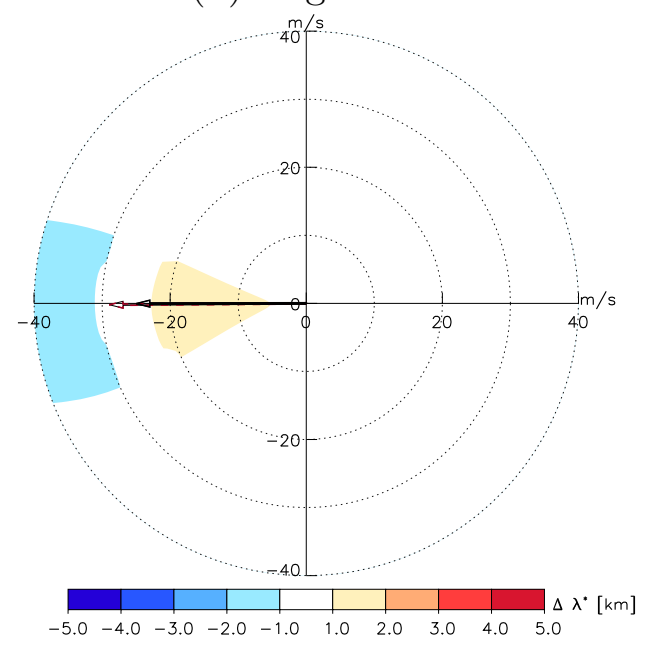

(d)

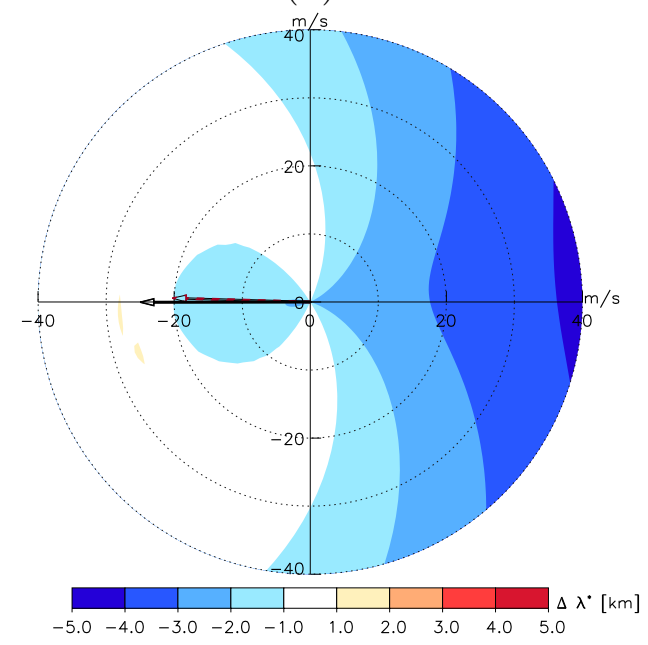

Figure 6. a) Critical horizontal wavelengths (shaded) for the $24-26 \mathrm{~km}$ layer during days 31-33 in Regime $1 \lambda_{R 1 U}^{*}$. The blue circle marks the critical level where $c=U$. The black arrow indicates the mean environmental wind. b) Difference in $\lambda_{R 1 U}^{*}$ and $\lambda^{*}$ for layer $24-26 \mathrm{~km}$ during days 38-40 in Regime $2 \lambda_{R 2 U}^{*}-\lambda_{R 1 U}^{*}$. c) and d): Similar to b) but for layer 18-20 km during days 31-33 in Regime $1 \lambda_{R 1 L}^{*}-\lambda_{R 1 U}^{*}$ and days 38-40 in Regime $2 \lambda_{R 2 L}^{*}-\lambda_{R 1 U}^{*}$, respectively. 


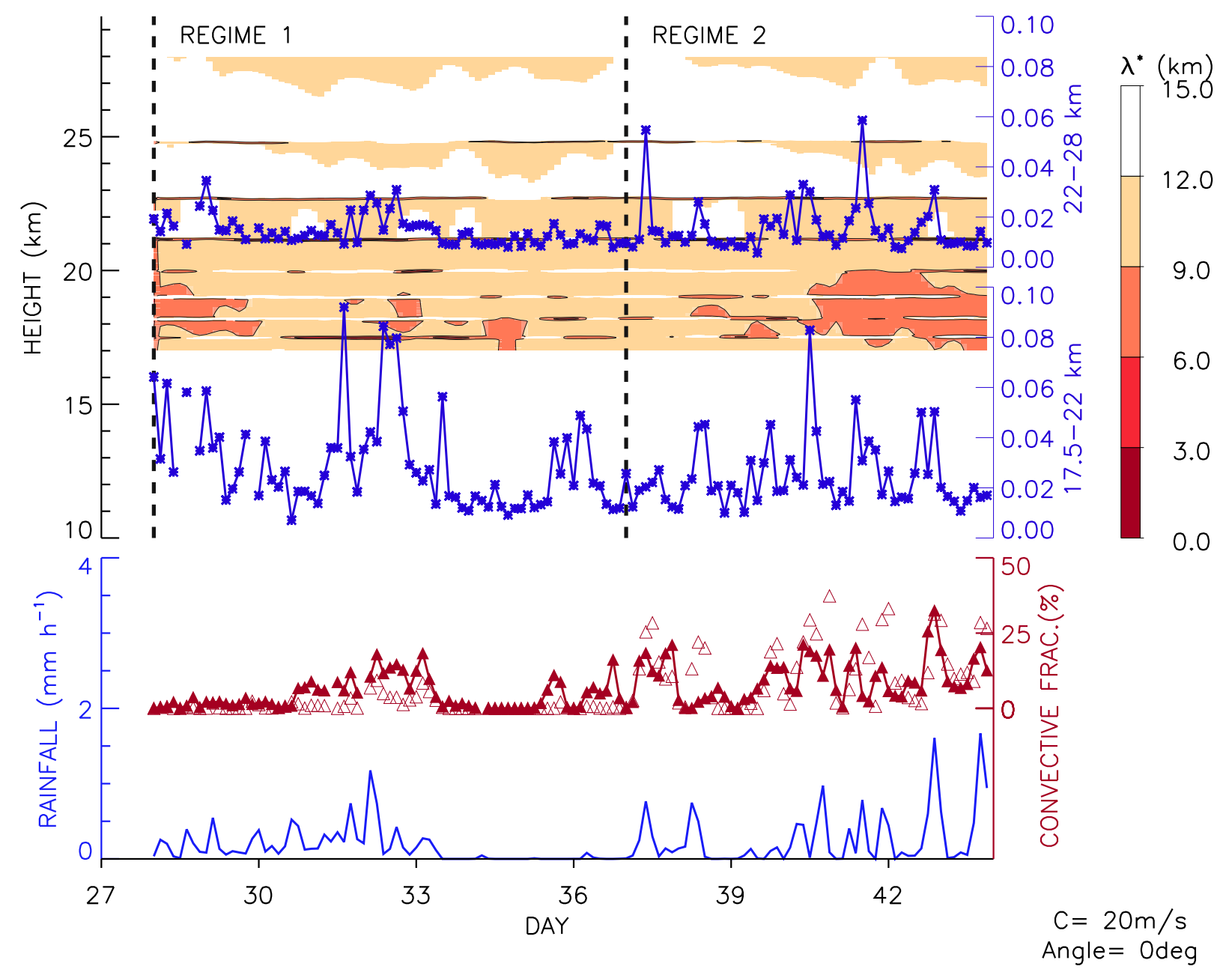

Figure 7. Upper panel: Evolution of the critical wavelength $\lambda^{*}$ (shaded) and the wave activity $\overline{\rho w^{\prime 2}}$ in the $22-28 \mathrm{~km}$ layer (top line with asterisks) and the $17.5-22 \mathrm{~km}$ (second line from top with asterisks). Lower panel: Time series of convection coverage within $150 \mathrm{~km}$ radius (red open triangles) and between 150 and $300 \mathrm{~km}$ radii (red filled triangles) from Darwin, and the area-averaged convective rain rates (solid blue line) estimated by C-pol radar centred at Darwin. 
(a)

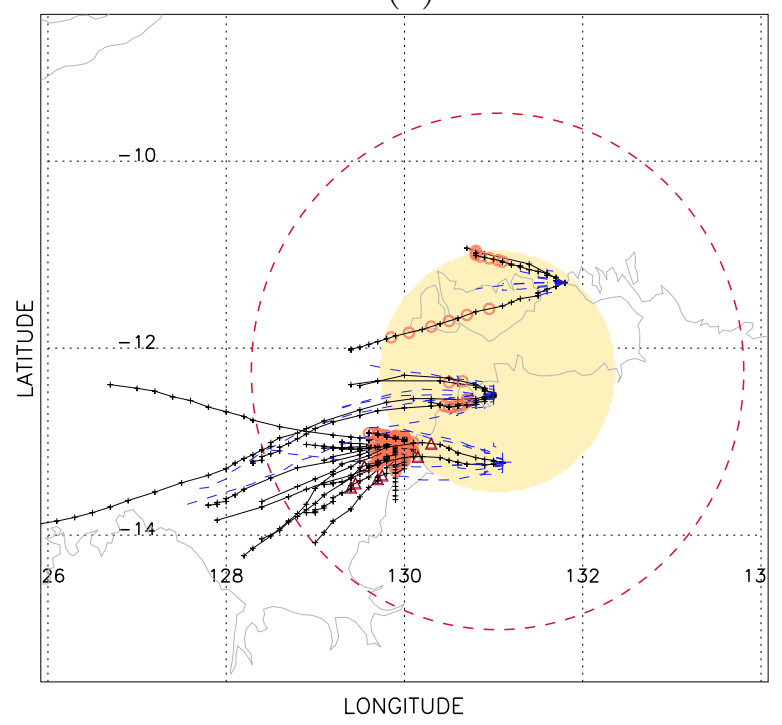

(b)

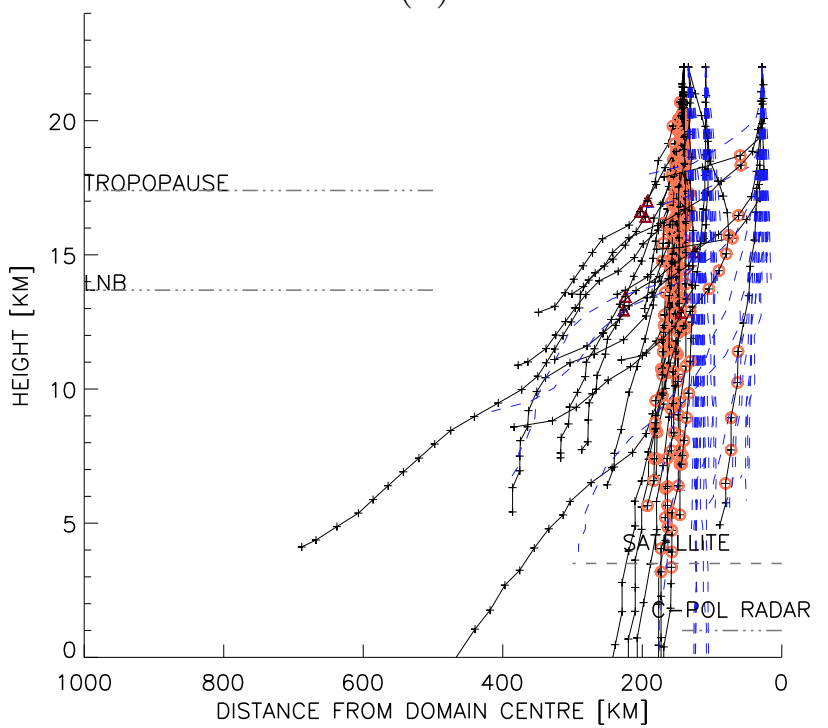

Figure 8. Backward ray-tracing results for 00Z day 36. Black solid (dashed blue) lines show rays that do (do not) pass over convective regions. Red triangles (brown circles) mark deep (shallow) convection. Convection is identified along a section between two consecutive points of ray paths if convection coverage is at least $10 \%$ in the $1^{\circ} \times 1^{\circ}$ box centered in the middle of the section. Radar coverage area is shaded. Dashed red circle shows the 300-km radius, within which satellite data were used for estimating convective activity in Figure 7. (a) Horizontal plane view, (b) Distance-Height view. Distance is calculated from the location of C-Pol radar at (131.044 E,12.249 S). 


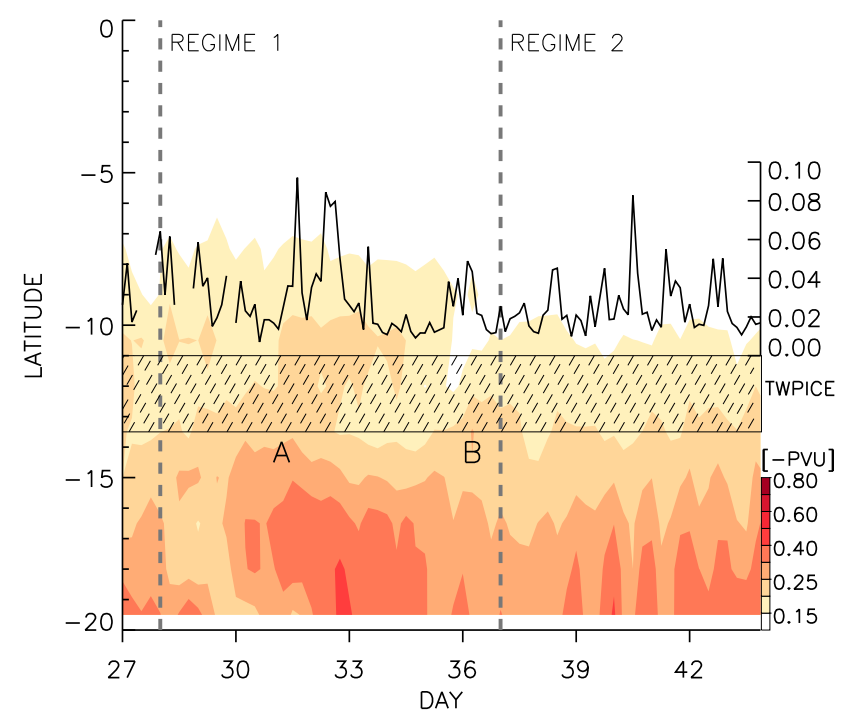

Figure 9. Time-latitude Hovmöller diagram (shaded) of the low-level tropospheric potential vorticity at $130^{\circ} \mathrm{E}$ longitude and in the layer between the $310 \mathrm{~K}$ and $320 \mathrm{~K}$ isentropic surfaces. The solid line shows the wave activity in the stratosphere $(17.5-28 \mathrm{~km})$ averaged over stations. Potential vorticity is calculated from the ERAI dataset with $1.5 \times 1.5$-degree horizontal resolution. Latitudes of the TWP-ICE domain are marked with the dashed box. 